\title{
An Historical Analysis of the California Current Circulation Using ROMS 4D-Var. Part I: System Configuration and Diagnostics
}

\author{
Emilie Neveu ${ }^{1}$, Andrew M. Moore ${ }^{2 *}$, Christopher A. Edwards ${ }^{2}$, Jérôme Fiechter ${ }^{2}$, \\ Patrick Drake ${ }^{2}$, William J. Crawford ${ }^{2}$, Michael G. Jacox ${ }^{3,4}$ and Emma Nuss ${ }^{5}$ \\ 1 INRIA, Rhonee Alpes Research Center, Grenoble, France. \\ 2 Department of Ocean Sciences, 1156 High Street \\ University of California, Santa Cruz CA 95062. \\ 3 Institute or Marine Sciences, 1156 High Street \\ University of California, Santa Cruz CA 95062. \\ 4 Environmental Research Division, Southwest Fisheries Science Center \\ NOAA, Monterey, California. \\ 5 Department of Oceanography, \\ University of Hawai'i at Manoa, Honolulu HI 96822. \\ * Corresponding author: ammoore@ucsc.edu
}

November 9, 2015 
Abstract

1 The Regional Ocean Modeling System (ROMS) 4-dimensional variational (4D-Var) data 2 assimilation tool has been used to compute two sequences of circulation analyses for the 3 U.S. west coast. One sequence of analyses spans the period 1980-2010 and is subject to 4 surface forcing derived from relatively low resolution atmospheric products from the Cross${ }_{5}$ Calibrated Multi-Platform wind product (CCMP) and the European Centre for Medium 6 Range Weather Forecasts (ECMWF) reanalysis project. The second sequence spans the 7 shorter period 1999-2012 and is subject to forcing derived from a high resolution product from 8 the Naval Research Laboratory Coupled Ocean Atmosphere Mesoscale Prediction System 9 (COAMPS). The two analyses periods are divided into eight day windows, and all available

satellite observations of sea surface temperature and sea surface height, as well as in situ hydrographic profiles are assimilated into ROMS using 4D-Var. The performance of the system is monitored in terms of the cost function and the statistics of the innovations, and the impact of data assimilated on the circulation is assessed by comparing the posterior circulation estimates with the prior circulation and the circulation from a run of the model without data assimilation, with particular emphasis on eddy kinetic energy. This is part I of a two part series, and the circulation variability of the $4 \mathrm{D}$-Var analyses is documented in part II.

Keywords: California Current; data assimilation; 4D-Var. 


\section{${ }_{19} \mathbf{1}$ Introduction}

The California Current System (CCS) is the dominant circulation feature along the west coast of North America where equatorward winds drive coastal upwelling, leading to high levels of primary productivity. The CCS is the eastern boundary current of the North Pacific subtropical gyre, and the dynamics of this region are of interest because of the associated energetic mesoscale circulation and pronounced seasonal cycle of upwelling, especially important in central California from April to July (Hickey, 1979, 1998; Checkley and Barth 2009). The CCS and associated ecosystems are influenced by known modes of climate variability, such as the El Niño Southern Oscillation (ENSO) (e.g. Lynn and Bograd, 2002), the Pacific Decadal Oscillation (PDO) (Mantua et al., 1997), and the North Pacific Gyre Oscillation (NPGO) (Di Lorenzo et al., 2009).

This paper is the first of a two part series that describes a sequence of retrospective analyses of the CCS circulation computed using a high resolution configuration of the Regional Ocean Modeling System (ROMS) in conjunction with 4-dimensional variational (4D-Var) data assimilation, spanning the period Jan. 1980 to Dec. 2012. In contrast to most previous analyses of the CCS that are available from global data assimilation products (such as those available through the Global Ocean Data Assimilation Experiment (GODAE)), the analyses described here were performed at a resolution that largely captures the mesoscale circulation and the influence of complex coastal geometry and bathymetry. Furthermore, other analyses of the CCS are more limited in time and do not adequately resolve low-frequency variability. Another and original feature of our analyses is that they utilize some of the best high resolution atmospheric forcing products that are available from regional atmospheric 
models and regional reanalyses, which resolve many important features of the surface forcing such as wind intensification in the vicinity of capes (Castelao and Barth 2006) and local topographically enhanced wind stress curl (Enriquez and Friehe 1995; Doyle et al, 2009), although excessive wind stress curl near the coast can be detrimental to model circulation estimates as well (Capet et al, 2004).

While regional circulation models, such as ROMS, have been developed for modeling the complex coastal circulation environment, they provide accurate analyses of the physical circulation only if the initial conditions, boundary conditions and model parameters are accurately specified. Data assimilation methods can be used to estimate these inputs to the model by identifying the best linear unbiased estimate (BLUE) of the circulation, which in the case of linear dynamics and Gaussian errors, is equivalent to the maximum likelihood estimate.

Data assimilation can also be formally related to Bayes' theorem. The circulation obtained from a model is uniquely determined by the initial conditions, boundary conditions, and model parameters, which are referred to collectively as the control variables. We will denote by $\mathbf{z}$ the vector of control variables, and by $\mathbf{y}^{o}$ the vector of ocean observations. Treating both $\mathbf{z}$ and $\mathbf{y}^{o}$ as random variables, Bayes' theorem relates the conditional probability distribution of the unknown control variables given the observations, denoted $P\left(\mathbf{z} \mid \mathbf{y}^{o}\right)$, to the prior distribution $P(\mathbf{z})$ of the unknowns $\mathbf{z}$ and the data distribution $P\left(\mathbf{y}^{o} \mid \mathbf{z}\right)$ which quantifies the distribution of the measurement errors in relation to the unknowns z. Formally Bayes' theorem can be expressed as:

$$
P\left(\mathbf{z} \mid \mathbf{y}^{o}\right)=P\left(\mathbf{y}^{o} \mid \mathbf{z}\right) P(\mathbf{z}) / P\left(\mathbf{y}^{o}\right)
$$


where $P\left(\mathbf{y}^{o}\right)$ is the marginal probability distribution and acts a normalizing coefficient to ensure that the integral of $P\left(\mathbf{z} \mid \mathbf{y}^{o}\right)$ is one. It is usual to express the observations as $\mathbf{y}^{o}=$ $H\left(\mathbf{z}_{t}\right)+\epsilon$ where $H$ is called the observation operator and $\mathbf{z}_{t}$ represents the true control vector. The vector of observation errors $\epsilon$ has a covariance given by $\mathbf{R}$, and the observation operator $H$ may include the model equations. For Gaussian distributed errors in $\mathbf{z}$ and $\mathbf{y}^{o}$, then $P\left(\mathbf{z} \mid \mathbf{y}^{o}\right) \propto \exp \left(-\mathcal{J}_{N L}\right)$, where:

$$
\mathcal{J}_{N L}=\frac{1}{2}\left(\mathbf{z}-\mathbf{z}^{b}\right)^{T} \mathbf{D}^{-1}\left(\mathbf{z}-\mathbf{z}^{b}\right)+\frac{1}{2}\left(\mathbf{y}^{o}-H(\mathbf{z})\right)^{T} \mathbf{R}^{-1}\left(\mathbf{y}^{o}-H(\mathbf{z})\right) .
$$

In (2) $\mathbf{z}^{b}$ is the prior control vector and $\mathbf{D}$ is the covariance of the errors in the prior. Data assimilation can then be viewed as identification of the control vector $\mathbf{z}$ that maximizes the conditional probability $P\left(\mathbf{z} \mid \mathbf{y}^{o}\right)$ (Wikle and Berliner, 2007). According to (2), $P\left(\mathbf{z} \mid \mathbf{y}^{o}\right)$ will be a maximum when $\mathcal{J}_{N L}$ has its minimum value. In control theory, $\mathcal{J}_{N L}$ is usually referred to as the cost function or penalty function.

Variational approaches are often used to identify the $\mathbf{z}$ that minimizes $\mathcal{J}_{N L}$, and were first introduced in meteorological applications by Lewis and Derber (1985), Le Dimet and Talagrand (1986), and Talagrand and Courtier (1987). During 4D-Var, the model is used to dynamically interpolate in space and time (via $H$ ) all of the information gathered by the irregular sampling of the observations, resulting in a 4D picture of the ocean circulation that represents the BLUE during the period spanned by the observations. Two approaches are generally used: one in which the minimization of $\mathcal{J}_{N L}$ is performed in the space spanned by the control vector, referred to as the primal approach, and one in which the minimization of $\mathcal{J}_{N L}$ is performed in the space spanned by the observations, referred to as the dual approach. 
Since the control vector is usually much larger than the number of ocean observations, the dual approach is potentially more amenable in high resolution models. Only a handful of ocean models use the 4D-Var approach, including MITgcm (Wunsch and Heimbach, 2007), the Ocean Parallèlisè (OPA) model (Weaver et al., 2003), the Nucleus for European Modelling of the Ocean (NEMO; Mogensen et al., 2012), the Navy Coastal Ocean Model (NCOM; Ngodock and Carrier, 2013) and ROMS (Moore et al., 2011a; Kurapov et al., 2009). However, ROMS is somewhat unique in terms of the tools that are available in support of both the primal or dual approaches. Moore et al., (2011a,b,c) describe in detail all of the features currently available for the ROMS 4D-Var systems.

The current application of ROMS 4D-Var to the CCS was preceeded by the studies of Broquet et al. $(2009,2011)$ which were important in demonstrating the 4D-Var approach and methodology that is used here. In the present study, we have extended this previous work and compute historical analyses of the CCS spanning two different periods: the 31 year period 1980-2010 (hereafter referred to as WCRA31), and the 14 year period 19992012 (hereafter WCRA14). During WCRA31, the model surface forcing was derived from a combination of atmospheric products with horizontal resolutions ranging from 25-200 km. While these products capture well the large-scale components of the atmospheric circulation, as noted earlier, the coastal orography can significantly influence the near-shore atmospheric circulation. Therefore during WCRA14 the model was forced by a higher resolution product with a resolution ranging from 3-9km. As such, during the overlapping period 1999-2010, WCRA14 and WCRA31 demonstrate the impact of high resolution forcing on the ocean circulation estimates. The companion paper by Crawford et al. (2014), hereafter referred to as Part II, explores the circulation variability within WCRA31 and its relation to ENSO, 
the NPGO and the PDO.

It should also be mentioned that there have been other significant data assimilation efforts in the context of the CCS. Li et al $(2008,2009)$ and Chao et al (2009) describe a 3D-Var data assimilation system for ROMS which is also currently used to compute nowcasts and forecasts for the CCS. Pan et al (2011) and Ngodock and Carrier (2013) have also used 3DVar and 4D-Var respectively in conjunction with the Navy Coastal Ocean Model (NCOM), although this was mainly a study of the Monterey Bay. 4D-Var circulation estimates of the CCS off the Oregon coast have been computed by Kurapov et al $(2009,2011)$ and Yu et al (2012) using the Advanced Variational Regional Ocean Representer Analyzer (AVRORA), also applied in ROMS. Circulation estimates of the CCS have also been computed using a non-incremental formulation of 4D-Var in the MITgcm by Todd et al (2011). A more detailed review of these and other efforts can be found in Edwards et al (2015).

An outline of the paper is as follows. In section 2, we describe ROMS-CCS and discuss the prior information and observations that are critical for identifying the BLUE using equations (1) and (2). Section 3 introduces the 4D-Var set-up, discusses quality control of the observations, the minimization procedure, and the prior error statistics. In section 4 , the performance of the minimization algorithm is discussed, along with a diagnostic analysis of the innovation statistics. Differences between the posterior and prior estimates are examined in section 5, and the analyses are validated by comparing them to a run of the model without assimilation. Comparisons with the assimilated data set are also presented. We conclude with a summary and discussion in section 6 where limitations of the current analyses are discussed. 
127

128

\section{ROMS CCS: Model Set-up, Priors, and Observa-}

\section{tions}

In this section, we present the configuration of ROMS for the CCS, and motivate our choice of prior information for the surface forcing and boundary conditions used to compute WCRA31 and WCRA14. A description of the observations assimilated into the model is also presented along with details of observation pre-processing.

\subsection{The ROMS configuration}

ROMS is a Boussinesq, hydrostatic, primitive equations ocean model, and is well suited for modeling coastal regions characterized by complex topography and bathymetry because of its advanced numerics (Shchepetkin and McWilliams, 2004). ROMS possesses an extensive suite of numerical algorithms for advection and diffusion of momentum and tracers, as well as a variety of parameterizations for horizontal and vertical mixing and open boundary conditions. A full description of ROMS can be found at http://www.myroms.org. Following Veneziani et al. (2009a) and Broquet (2009), the CCS domain spans the region $30^{\circ} \mathrm{N}-48^{\circ} \mathrm{N}$, $134^{\circ} \mathrm{W}-115.5^{\circ} \mathrm{W}$ and is shown along with the bathymetry in Fig. 1.

The horizontal resolution is $1 / 10^{\circ}$, while in the vertical 42 terrain-following $\sigma$-levels were used that vary in thickness between $0.3-8 \mathrm{~m}$ over the continental shelf and $7-100 \mathrm{~m}$ in the deep ocean. A prerequisite for data assimilation is a model capable of generating a good prior estimate of the circulation. Veneziani et al. (2009a) have demonstrated that the current configuration of ROMS CCS captures very well many aspects of the observed circulation, and Broquet et al. (2009, 2011) have shown that it performs well in 4D-Var experiments. 
While Marchesiello et al (2003) find that a resolution of at least $\sim 1 / 20^{\circ}$ is required to represent coastal upwelling and the circulation energetics in this region, the choice of $1 / 10^{\circ}$ resolution used here represents a trade-off between resolution of the smaller scale features of the circulation and the computational cost of the 4D-Var approach. Nevertheless, the resolution used here is adequate to capture much of the variability associated with mesoscale eddies which vary in size between 40 and $350 \mathrm{~km}$, with a mean size of $\sim 165 \mathrm{~km}$ (Stegmann and Schwing, 2007).

Following Moore et al. (2011a), the ROMS state-vector of grid-point prognostic variables will be referred to as $\mathbf{x}$ and comprises the potential temperature $T$, the salinity $S$, horizontal velocities $(\mathbf{u}, \mathbf{v})$, and sea surface displacement $(\zeta)$ :

$$
\mathbf{x}=(T, S, \zeta, \mathbf{u}, \mathbf{v})^{T}
$$

where superscript $T$ denotes the vector transpose. For ease of notation, the non-linear ROMS will be denoted in sequel by $M\left(t_{i}, t_{i-1}\right)$, so that:

$$
\mathbf{x}\left(t_{i}\right)=M\left(t_{i}, t_{i-1}\right)\left(\mathbf{x}\left(t_{i-1}\right), \mathbf{f}\left(t_{i-1}, t_{i}\right), \mathbf{b}\left(t_{i-1}, t_{i}\right)\right) .
$$

The vector $\mathbf{x}\left(t_{i}\right)$ represents the propagation in time by the discretized model subject to surface forcing, $\mathbf{f}\left(t_{i-1}, t_{i}\right)$, and lateral open boundary conditions, $\mathbf{b}\left(t_{i-1}, t_{i}\right)$, during the time interval $\left[t_{i-1}, t_{i}\right]$. In the ROMS data assimilation system and in keeping with Bayes' theorem, the surface forcing and boundary conditions are regarded as prior information, and are actually control variables in that they are adjusted during the data assimilation procedure. In sequel, the prior vectors of surface forcing and boundary conditions are denoted $\mathbf{f}^{b}$ and 
$\mathbf{b}^{b}$ respectively.

\subsection{Prior surface forcing}

The prior surface forcing $\mathbf{f}^{b}$ comprises surface fluxes of momentum, heat and freshwater estimated from different sources of atmospheric data. For WCRA14 daily-averaged atmospheric variables at standard heights from the Naval Research Laboratory's Coupled OceanAtmosphere Mesoscale Prediction System (COAMPS) were used. The COAMPS forcing is derived from a series of nested grids (Doyle et al., 2009) and the combined product used here has a resolution of $\sim 3-9 \mathrm{~km}$. Since COAMPS data is available only since January 1999, the surface forcing for WCRA31 (starting in 1980) was derived from a combination of sources. Specifically, the 40 year reanalysis from ECMWF (ERA40; Källberg et al., 2004) with a resolution of $2.5^{\circ}$ was used for the period 1980-2001 and the more recent ECMWF interim reanalysis (ERA Interim; Dee et el., 2011) with a resolution of $0.7^{\circ}$ for the period 2002-2010, along with the Cross-Calibrated, Multi-Platform (CCMP) ocean wind product of Atlas et al. (2011) with a resolution of $25 \mathrm{~km}$ that spans the period 1988-2010. In both WCRA14 and WCRA31, the ocean surface fluxes were computed using the bulk formulations of Liu et al. (1979) and Fairall et al. (1996a,b). As described by Atlas et al. (2011), CCMP is an analysis of surface winds computed using a 2D-Var procedure in which ERA40 was used as the 2DVar prior estimate. Therefore, to ensure consistency between the CCMP-derived wind stress and surface heat and freshwater fluxes used to force ROMS, we chose to use the ERA40 fields at $2.5^{\circ}$ resolution as the $4 \mathrm{D}$-Var prior in ROMS during the period spanned by CCMP, rather than the higher resolution $(75 \mathrm{~km})$ ERA Interim product, sacrificing resolution for consistency between the various components of the surface forcing. 


\subsection{Prior open boundary conditions}

Clamped time varying boundary conditions were used for tracers and momentum at all open boundaries for both WCRA31 and WCRA14. The prior open boundary conditions $\mathbf{b}^{b}$ were taken from the global Simple Ocean Data Assimilation Product (SODA; version SODA POP 2.2.4) of Carton and Giese (2008). The Chapman (1985) boundary conditions were applied to sea surface height, while the vertically integrated flow was subject to the Flather (1976) condition. To damp boundary waves, a $100 \mathrm{~km}$ wide sponge layer was also used adjacent to the open boundaries, in which viscosity increased linearly from $4 \mathrm{~m}^{2} \mathrm{~s}^{-1}$ in the interior to $400 \mathrm{~m}^{2} \mathrm{~s}^{-1}$ at the boundary.

\subsection{Observations}

During both WCRA31 and WCRA14, all available observations from in-situ instruments and satellite platforms were assimilated into the model. An important first step in reducing data redundancy is the pre-processing of observations that combines all observations of the same state variable within each model grid cell over a 6 hour time window to form superobservations. During 4D-Var, the contribution of each observation to the posterior control vector is weighted according to the sum of the variance of measurement error and the error of representativeness. Observation errors and errors of representativeness are assumed to be mutually uncorrelated in space and time resulting in a diagonal observation error covariance matrix $\mathbf{R}$ in (2). While this is unlikely to be true in general, especially for gridded satellite data, specification of correlated observation error is non-trivial, and greatly complicates the 4D-Var procedure. This is discussed further in section 3. 
A summary of the different observation platforms and the nominal error standard deviations assigned to each platform are shown in Table 1. After the computation of super observations, the variance entries in $\mathbf{R}$ were replaced by the sum of the variance of the individual observations about the value of the super observation (taken as an estimate of the error of representativeness) and the nominal error variance in Table 1 . The super observations procedure affects nearly every observation since satellite observations are averaged in the horizontal and in situ observations in the vertical to match the model resolution.

Figure 2 shows a time series of $\log _{10}$ of the total number of super observations from each observing platform that fall within the ROMS CCS model domain during each month of the year spanning the full period of WCRA31. Figure 2 indicates that the bulk of the observations available for assimilation are in the form of satellite measurements of SST. As indicated in Table 1, SST observations are available from several different platforms. The along track data from each platform were used, and when multiple platforms are concurrently available, the super observations from each platform were combined via the super observation process. Only the number of super observations for each individual platform are shown in Fig. 2. The individual super observations from each platform were combined, if necessary, by computing a standard minimum variance estimate using the nominal errors in Table 1 to compute the weights. While it can be argued that the formation of super observations effectively reduces the uncertainty in the assimilated data, no effort was made here to reduce the error entries in $\mathbf{R}$ associated with super observations.

The SSH data used here were from the multi-mission $1 / 4^{\circ}$ global SSH fields created by the Archiving Validation and Interpretation of Satellite Oceanographic data center (AVISO), specifically their Data Unification and Altimeter Combination System (DUACS) version DT- 
2010. These SSH data are produced by objective mapping of multi-mission altimeter data (Dibarboure et al. 2011), and the data assimilated into the model was a 1 day gridded composite. Prior to assimilating the data, the mean dynamic topography of the AVISO data averaged over the ROMS CCS domain was corrected to match that of the model. A steric height correction was also applied using the data of Willis et al. (2004). Rather than using along-track data, gridded data were used because the version of 4D-Var employed to compute the analyses does not allow for prior errors or observation errors that are correlated in time. As a result, information from individual along track observations can be quickly lost due to geostrophic adjustment and becomes ineffective for constraining the model unless it persists over time. This issue can be alleviated using the gridded products, which allows the large-scale gyre circulation and eddy field to geostrophically adjust to the SSH field. However, this is not an ideal solution because of the limitations of the objective mapping technique used to map the altimeter observations onto a regular grid. Furthermore, since satellite SSH observations near the coast are known to be unreliable (Saraceno et al., 2008), only observations more than $50 \mathrm{~km}$ from the coast were assimilated.

The in-situ hydrographic profiles of $T$ and $S$ assimilated into the model were taken from the quality controlled EN3 data archive maintained by the UK Met Office as part of the European Union ENSEMBLES project (Ingleby and Huddleston, 2007). These observations are available from a variety of different observing platforms that include: expendable bathythermographs (XBTs), mechanical bathythermographs (MBTs), conductivity temperature depth devices (CTDs), free drifting Argo profiling floats, and autonomous pinneped bathythermographs (APBs) in the form of tagged marine mammals. The version of EN3 used here is version 2a which includes the XBT and MBT temperature error corrections of 
Levitus et al. (2009). No velocity observations were assimilated into the model. However, work is underway to augment the observations assimilated into the ROMS system described here with coastal HF radar observations of surface current that cover the entire U.S. West Coast out to approximately $100 \mathrm{~km}$ offshore (Oke et al., 2015).

\section{The incremental 4D-Var system}

As noted in Section 1, the circulation of an ocean model is uniquely determined by the initial conditions, surface forcing and boundary conditions. In (2) these were identified as the control variables, $\mathbf{z}$, which we can now write as $\mathbf{z}=\left(\mathbf{x}\left(t_{0}\right)^{T}, \mathbf{f}^{T}, \mathbf{b}^{T}\right)^{T}$ where $\mathbf{x}\left(t_{0}\right)$ represents the initial state vector, while $\mathbf{f}$ and $\mathbf{b}$ are vectors of surface forcing and open boundary conditions at all time steps within the data assimilation window. Similarly, the vector of prior control variables is denoted by $\mathbf{z}^{b}=\left(\mathbf{x}^{b}\left(t_{0}\right)^{T}, \mathbf{f}^{b^{T}}, \mathbf{b}^{b^{T}}\right)^{T}$. The prior control vector yields an estimate that may differ significantly from the observations which, following (2), are denoted by $\mathbf{y}^{o}$. Variational data assimilation seeks to identify the control vector $\mathbf{z}^{a}$ that minimizes the cost function in (2) which is a measure of the distance, in a Mahalanobis sense, between $\mathbf{z}$ and $\mathbf{z}^{b}$ as well as $\mathbf{y}^{o}$ and the projection of $\mathbf{z}$ into observation space. The weighting functions used are the inverse prior error covariance matrix and inverse observation error covariance respectively.

The 4D-Var data assimilation method employed here is iterative, starting from the prior $\mathbf{z}^{b}$, and it searches for a sequence of new $\mathbf{z}$ iterates that yield successively smaller values of $\mathcal{J}_{N L}$. The minimum of $\mathcal{J}_{N L}$ identifies $\mathbf{z}^{a}$, the desired posterior estimate of $\mathbf{z}$ that maximizes the conditional probability $P\left(\mathbf{z} \mid \mathbf{y}^{o}\right)$ in (1). Since $H$ is generally non-linear, the cost function 
$\mathcal{J}_{N L}$ will be non-quadratic, and being non-convex may possess more than one minimum solution. Therefore, it is more usual to employ a Gauss-Newton approach to minimize $\mathcal{J}_{N L}$. In this case a sequence of quadratic cost functions are minimized by linearizing the model and the observation operator (Lawless et al. 2005). This approach developed in numerical weather prediction (NWP) is referred to as the incremental method (Courtier et al., 1994), and proceeds by assuming that each estimate of $\mathbf{z}_{k}$ is a small departure $\delta \mathbf{z}$ from the prior, so that $\mathbf{z}_{k}=\mathbf{z}^{b}+\sum_{l=1}^{k-1} \delta \mathbf{z}_{l}$, where $k$ refers to the $k^{\text {th }}$ outer-loop iterate, and $\delta \mathbf{z}_{l}$ are the increments from all previous outer-loops given by:

$$
\delta \mathbf{z}_{l}=\left(\delta \mathbf{x}\left(t_{0}\right)_{l}^{T}, \delta \mathbf{f}_{l}^{T}, \delta \mathbf{b}_{l}^{T}\right)^{T}
$$

where $\delta \mathbf{x}\left(t_{0}\right)_{l}, \delta \mathbf{f}_{l}$ and $\delta \mathbf{b}_{l}$ denote the increments in the initial conditions, surface forcing and open boundary conditions. In the calculations described here, only a single outer-loop was considered, so the subscript $k$ will be dropped in subsequent expressions.

The state-vector increment $\delta \mathbf{x}$ is a solution of the tangent linearization of the model $M$ in (4) linearized about the prior state $\mathbf{x}^{b}, \mathbf{f}^{b}$ and $\mathbf{b}^{b}$, and subject to the increments $\delta \mathbf{f}$ and $\delta$ b, namely:

$$
\delta \mathbf{x}\left(t_{i}\right)=\mathbf{M}\left(t_{i}, t_{0}\right) \delta \mathbf{z}
$$

where $\mathbf{M}\left(t_{i}, t_{0}\right)$ is the tangent linear model. The quadratic cost function $\mathcal{J}$ in terms of the control vector increment $\delta \mathbf{z}$ is given by:

$$
\mathcal{J}=\frac{1}{2} \delta \mathbf{z}^{T} \mathbf{D}^{-1} \delta \mathbf{z}+\frac{1}{2}(\mathbf{d}-\mathbf{G} \delta \mathbf{z})^{T} \mathbf{R}^{-1}(\mathbf{d}-\mathbf{G} \delta \mathbf{z})
$$


which is the weighted sum of the squared increments $\delta \mathbf{z}$ and the squared departures of the time evolved increments from the innovation vector $\mathbf{d}=\mathbf{y}^{o}-H\left(\mathbf{x}^{b}\right)$. The operator $\mathbf{G}$, referred to as the generalized observation operator, is a convolution in time of $\mathbf{M}$ with $\mathbf{H}$, where $\mathbf{H}$ is the tangent linearization of the observation operator $H$, so that $\mathbf{G}$ represents the tangent linear model sampled at the observation points. Each $\delta \mathbf{z}_{l}$ in (5) corresponds to the minimization of $\mathcal{J}$ in (7) where $\mathbf{G}$ is linearized about $\mathbf{z}_{l-1}$ and is identified by a sequence of inner-loops iterations. In the case a single outer-loop the final control vector is given by $\mathbf{z}^{a}=\mathbf{z}^{b}+\delta \mathbf{z}$

\subsection{The 4D-Var set-up}

As noted earlier, two analyses were performed, referred to as WCRA31 and WCRA14. The entire time interval in each case was divided into 8-day windows that are referred to as assimilation cycles. Each cycle overlaps the previous cycle and the next cycle by 4 days as illustrated in Fig. 3. In this way, the prior initial condition for each cycle is the posterior circulation estimate computed at the mid-point of the previous cycle. Overlapping cycles were used because each 4D-Var analysis cycle is equivalent to a Kalman smoother, for which the expected errors in the posterior analysis are a minimum at the mid-point of the cycle. Therefore the next cycle starts from the best possible prior initial state. While errors in the observations collected during the first half of a cycle will be correlated with errors in the prior circulation estimate, no account was taken of these correlations during the analyses presented here. The choice of an 8-day assimilation window was a trade-off between choosing an interval that includes a significant number of observations, and that does not seriously violate the tangent linear assumption which is invoked during 4D-Var. 
During each cycle, the cost function (7) was minimized using an iterative minimization algorithm based on a truncated Gauss-Newton method. Each member of the sequence was computed using 1 outer-loop and 15 inner-loop iterations, following Broquet et al. (2009), Moore et al. (2011b) and Gürol et al. (2013), who have demonstrated that this choice of parameters yields adequate convergence of $\mathcal{J}$ toward its minimum value.

In the calculations described here, the dual 4D-Var algorithm was used where the gain matrix is expressed as $\mathbf{K}=\mathbf{D G}^{T}\left(\mathbf{G D G}^{T}+\mathbf{R}\right)^{-1}$. The inverse of the stabilized representer matrix $\mathbf{S}=\left(\mathbf{G D G}^{T}+\mathbf{R}\right)$ (Bennett, 2002) was computed by solving an equivalent system of linear equations $\mathbf{S w}=\mathbf{d}$ using a conjugate gradient $(\mathrm{CG})$ algorithm. Following Gürol et al. (2013), $\mathbf{S}$ is preconditioned by $\mathbf{R}$ and a Lanczos formulation of CG was used in conjunction with a $\mathbf{G D G}^{T}$ inner-product to yield the Lanczos equivalent of the restricted D-preconditioned conjugate algorithm of Gratton and Tshimanga (2009). After the last outer-loop, the final increment was computed according to $\delta \mathbf{z}=\mathbf{D G}^{T} \mathbf{w} \equiv \mathbf{K} \mathbf{d}$.

\subsection{Observation error and prior error covariances}

In the observation error covariance matrix $\mathbf{R}$, it was assumed that the observation errors are not correlated in time or space in which case $\mathbf{R}$ is diagonal. The prior error covariance matrix, $\mathbf{D}$, is assumed to be block diagonal so that:

$$
\mathbf{D}=\operatorname{diag}\left(\mathbf{B}_{\mathbf{x}}, \mathbf{B}_{\mathbf{f}}, \mathbf{B}_{\mathbf{b}}\right)
$$

where $\mathbf{B}_{\mathbf{x}}, \mathbf{B}_{\mathbf{f}}$ and $\mathbf{B}_{\mathbf{b}}$ are the full multivariate prior error covariance matrices of the initial conditions, surface forcing and open boundary conditions respectively. Here we neglect 
the influence of model errors during the 4D-Var procedure (the so-called strong constraint), although some specific types of errors in terrain following coordinate models, such as ROMS, have been documented (e.g. Marchesiello et al, 2009). Accounting for model error during 4D-Var (the so-called weak constraint) is currently an active area of research, and will be the subject of a future study in ROMS. In addition, we assume that errors in the priors are neither correlated in time or flow-dependent, which renders $\mathbf{D}$ time invariant.

Each block of $\mathbf{D}$ in (8) was modeled using the diffusion operator approach introduced by Derber and Rosati (1989). In ROMS 4D-Var the approach developed by Weaver and Courtier (2001) was used in which the initial condition increment $\delta \mathbf{x}\left(t_{0}\right)$ is expressed as the sum of a balanced and unbalanced component of the circulation. The state variables of the unbalanced component of $\delta \mathbf{x}\left(t_{0}\right)$ are assumed to be uncorrelated with a covariance $\boldsymbol{\Sigma} \mathbf{C} \boldsymbol{\Sigma}^{T}$, where $\mathbf{C}$ is a univariate correlation matrix, and $\boldsymbol{\Sigma}$ is a diagonal matrix of standard deviations.

The initial condition prior error covariance matrix in ROMS, $\mathbf{B}_{\mathbf{x}}$ is factorized as:

$$
\mathbf{B}_{\mathbf{x}}=\mathbf{K}_{\mathbf{b}} \Sigma_{\mathbf{x}} \mathbf{C} \Sigma_{\mathbf{x}}^{T} \mathbf{K}_{\mathbf{b}}^{T}
$$

where $\mathbf{K}_{\mathbf{b}}$ is a multivariate balance operator. The implementation of $\mathbf{K}_{\mathbf{b}}$ used in ROMS parallels that of Weaver et al. (2005), Balmaseda et al. (2008) and Mogensen et al. (2013). All of the analyses described here were computed with the balance operator disabled. Nonetheless, the linearized dynamics embodied in the tangent linear and adjoint of ROMS effectively allows the transfer of information between variables during the assimilation procedure so the lack of $\mathbf{K}_{\mathbf{b}}$ during WCRA14 and WCRA31 is not considered to be detrimental to the re- 
sulting 4D-Var analysis. The prior error covariances for the surface forcing $\left(\mathbf{B}_{\mathbf{f}}\right)$ and open boundary conditions $\left(\mathbf{B}_{\mathbf{b}}\right)$ do not include a balance operator and are simply factorized as $\boldsymbol{\Sigma}_{\mathbf{f}} \mathbf{C}_{\mathbf{f}} \boldsymbol{\Sigma}_{\mathbf{f}}^{T}$ and $\boldsymbol{\Sigma}_{\mathbf{b}} \mathbf{C}_{\mathbf{b}} \boldsymbol{\Sigma}_{\boldsymbol{b}}^{T}$ respectively.

The standard deviations that comprise the diagonal elements of $\boldsymbol{\Sigma}_{\mathbf{x}}$ were chosen to be the climatological variance of a long run of the model subject only to surface forcing and boundary conditions (i.e. no data assimilation). However, in the case of salinity, past experience (Moore et al., 2013) has revealed that the background errors computed using this method are too large, so the standard deviations for $S$ were capped at $0.1 \mathrm{psu}$. In a similar vein, the temporal variability of the surface forcing fields for the appropriate period was used to compute the diagonal elements of $\boldsymbol{\Sigma}_{\mathbf{f}}$, and the elements of $\boldsymbol{\Sigma}_{\mathbf{b}}$ were chosen to be the standard deviations of the open boundary data. While the climatological variance is a useful proxy for the prior error variance during the initial 4D-var cycles, the prior error variance will naturally decrease over time as the model solution moves closer to the observations (see Fig. 7). Therefore the use of static climatological variances is inappropriate during later cycles, and the variances should evolve with the circulation. Flow-dependent covariance modeling is very challenging and is currently an active area of research. While no attempt was made here to refine the error covariance model parameters, we acknowledge that this places a limitation on the ensuing circulation analyses. Some of these limitations are explored in section 4.2.

Following Weaver and Courtier (2001), the univariate correlation matrix C is assumed to be separable in the horizontal and vertical, and the horizontal (vertical) correlation functions are modeled as the solution of a 2-dimensional (1-dimensional) pseudo-heat diffusion equation. The horizontal and vertical correlation lengths were held constant over the entire domain. The decorrelation length scales used to model the prior error covariances of each 
control variable are summarized in Table 2.

While no explicit account is taken of temporal correlations in any of the background errors in the current version of ROMS 4D-Var, the surface forcing and boundary condition increments were computed daily and interpolated to each intervening model time step. This procedure effectively imposes a temporal correlation on the errors. The correlation lengths for the prior errors must be specified a priori, and are typically estimated using semi-variogram techniques (e.g. Banerjee et al., 2004; Milliff et al., 2003; Matthews et al., 2011). However, some level of subjective tuning of the correlation lengths is also typically required to optimize the performance of the 4D-Var algorithm. A discussion of the choice of the aforementioned background error covariance parameters for the CCS in Table 2 can be found in Broquet et al. (2009, 2011) and Moore et al., (2011b).

\subsection{Background quality control}

A background quality control check was applied to the observations as a means of identifying data that cannot be well represented by the model because of measurement errors or inadequecies in the model (Hollingsworth et al., 1986, Lorenc and Hammon, 1988), and such data were rejected from the data assimilation system. Following Järvinen and Undén (1997) and Andersson and Järvinen (1999), the elements of the innovation vector d were compared with their expected error (assuming uncorrelated observation and background errors). Specifically, observations were rejected from the analysis based on the following criterion:

$$
\frac{\left(y_{i}^{o}-y_{i}^{b}\right)^{2}}{\sigma_{b}^{2}}>\alpha\left(1+\frac{\sigma_{o}^{2}}{\sigma_{b}^{2}}\right)
$$


where $y_{i}^{o}$ is the $i^{\text {th }}$ observation and $y_{i}^{b}$ the $i^{\text {th }}$ element of the vector $H\left(\mathbf{x}_{b}\right)$, the background evaluated at the observation locations. The standard deviations of the observation and background errors at the observation points are $\sigma_{o}$ and $\sigma_{b}$ respectively. While no attempt was made to propagate prior information about $\sigma_{b}$ to the appropriate observation times using the generalized observation operator $\mathbf{G}$, section 4.2 demonstrates that this is not a severe limitation. The threshold parameter $\alpha$ is dependent of the type of observation, and can be estimated from the frequency distribution of the elements of $\mathbf{d}$ computed from historical analyses (Andersson and Järvinen, 1999). Since historical analyses are not available in the present case, we considered instead the innovations from a randomly chosen year (1999) during which all observations were assimilated into the model. Based on the analysis described by Moore et al. (2013), the background quality control parameter $\alpha=16$ was found to be appropriate for the 4D-Var system described here. In other words, an observation that produces a misfit greater than $4\left(\sigma_{b}^{2}+\sigma_{o}^{2}\right)^{\frac{1}{2}}$ is rejected. For this choice of $\alpha$, it was found that on average less than $1 \%$ of the observations were rejected during the $4 \mathrm{D}$-Var assimilation. A time series of the total number of observations rejected from the analysis each month is shown in Fig. 2. During most months $\sim 0.1 \%$ of the observations were rejected, although there are a few cycles, especially at the beginning of the analysis period, where the fraction of observations rejected was significantly higher (although still typically less than $2 \%$ ) due to the spin-up effects of the first few years. 
414

415

\section{Monitoring of $4 \mathrm{D}-\mathrm{Var}$}

\subsection{Minimization}

The 4D-Var cost function is a useful indicator of the performance of the minimization algorithm. Figure 4 shows time series of the prior and posterior cost function $\mathcal{J}$ in (7) for each data assimilation cycle, for both WCRA31 and WCRA14. The posterior cost function is always less than the prior cost function, typically by a factor of $\sim 2-5$, indicating that the minimization algorithm is behaving correctly. Also shown in Fig. 4 are the values of the non-linear cost function $\mathcal{J}_{\mathrm{NL}}$ from (2), which recall is a measure of the misfit between the non-linear model and the observations and between the non-linear model and the prior. During the majority of cycles of WCRA31, $\mathcal{J}_{\mathrm{NL}} \sim \mathcal{J}$ indicating that the tangent linear assumption of the incremental approach is generally valid. Discrepancies between $\mathcal{J}_{\mathrm{NL}}$ and $\mathcal{J}$ are generally larger during WCRA14, and during a few cycles the posterior $\mathcal{J}_{\mathrm{NL}}$ is larger than the prior value. This behavior is associated with non-linearity and may be due to the higher resolution of the forcing used in WCRA14 which enhances non-linear circulation effects in the model. Nonetheless, even though the discrepancies between $\mathcal{J}_{\mathrm{NL}}$ and $\mathcal{J}$ are larger for WCRA14 than for WCRA31, on the whole WCRA14 is well behaved also.

The time series of $\mathcal{J}$ also reflect changes in the observing network as different instrument platforms come online in accordance with Fig. 2. For example, in $1981 \mathcal{J}$ increases due to the introduction of SST observations from the Pathfinder AVHRR satellite, and then again in 2000 due to the introduction of SST observations from MODIS. 


\subsection{Innovation statistics}

The statistics of the innovation vectors $\mathbf{d}=\mathbf{y}^{o}-H\left(\mathbf{x}^{b}\right)$ provide valuable insight into the performance of the 4D-Var algorithm, and the choice of the prior error and observation error covariances. Figure 5 shows the probability density function (PDF) of the innovations from all cycles from WCRA31 for observations of temperature, salinity and sea surface height. The means for temperature, salinity and $\mathrm{SSH}$ are $-0.06^{\circ} \mathrm{C},-0.03 \mathrm{psu}$ and $-0.003 \mathrm{~m}$, respectively, and close to zero. The tails of the distributions indicate that the innovations sometimes have quite large values (e.g. in excess of $10^{\circ} \mathrm{C}$ for temperature; not shown). However, these occur very infrequently, and there is no particular preferred geographical location associated with the values in the tails (not shown). Also shown in Fig. 5 are normal distributions with the same mean and standard deviation as the PDFs. Clearly each PDF departs significantly from a normal distribution which indicates a violation of the hypotheses that underlie the 4D-Var system since the innovations should be normally distributed with zero mean and an error covariance of $\left(\mathbf{R}+\mathbf{G D G}^{T}\right)$.

The consistency of the prior error and observation error covariances prescribed in Section 3.2 with the 4D-Var estimates can be further examined following Desroziers et al. (2005). As noted above, the theoretical covariance of the innovations is given by $E\left\{\mathbf{d d}^{T}\right\}=(\mathbf{R}+$ GDG $^{T}$ ) where $E$ denotes the expectation operator. Following Desroziers et al. (2005), the innovation vector can also be expressed as $\mathbf{d}=\mathbf{y}^{o}-H\left(\mathbf{x}^{a}\right)+H\left(\mathbf{x}^{a}\right)-H\left(\mathbf{x}^{b}\right)=\mathbf{d}_{a}^{o}+\mathbf{d}_{b}^{a}$, where $\mathbf{d}_{a}^{o}=\mathbf{y}^{o}-H\left(\mathbf{x}^{a}\right)$ and $\mathbf{d}_{b}^{a}=H\left(\mathbf{x}^{a}\right)-H\left(\mathbf{x}^{b}\right)$, in which case $E\left\{\mathbf{d d}^{T}\right\}=E\left\{\mathbf{d}\left(\mathbf{d}_{a}^{o}\right)^{T}\right\}+E\left\{\mathbf{d}\left(\mathbf{d}_{b}^{a}\right)^{T}\right\}$ As shown by Desroziers et al. (2005), the theoretical expectation $E\left\{\mathbf{d}\left(\mathbf{d}_{a}^{o}\right)^{T}\right\}=\mathbf{R}$ while $E\left\{\mathbf{d}\left(\mathbf{d}_{b}^{a}\right)^{T}\right\}=\mathbf{G D G}^{T}$. Therefore, the vectors $\mathbf{d}_{a}^{o}$ and $\mathbf{d}_{b}^{a}$ provide information about the 
consistency of the statistics of the observation error covariance matrix and the prior error covariance in observation space (i.e. the representer matrix). As Desroziers et al. (2005) point out, the statistics of $E\left\{\mathbf{d}\left(\mathbf{d}_{a}^{o}\right)^{T}\right\}$ and $E\left\{\mathbf{d}\left(\mathbf{d}_{b}^{a}\right)^{T}\right\}$ will only match those specified a priori for $\mathbf{R}$ and $\mathbf{G D G}^{T}$ if the observation error and prior error statistics are chosen correctly.

Unfortunately, a direct measure of $\mathbf{G D G}^{T}$ is not readily available because it involves a mapping of $\mathbf{D}$ into observation space by the time evolving prior circulation. However, an estimate of the trace of $\mathbf{G D G}^{T}$ can be obtained using a randomization method (Andersson et al., 2000) which can be directly compared with the inner-product $\mathbf{d}^{T} \mathbf{d}_{b}^{a}$. Specifically, $\operatorname{Tr}\left(\mathbf{G D G} \mathbf{G}^{T}\right) \simeq 1 / M \sum_{i=1}^{M} \mathbf{q}_{i}^{T} \mathbf{q}_{i}$, where $\mathbf{q}_{i}=\mathbf{D}^{\frac{1}{2}} \mathbf{G}^{T} \mathbf{v}_{i}$ and $\mathbf{v}_{i}$ is a random vector sampled from a normal distribution with zero mean and unit standard deviation. The standard deviation of the sequence of estimates for $\operatorname{Tr}\left(\mathbf{G D G}^{T}\right)$ varies approximately as $1 /(2 M)^{\frac{1}{2}}$, so a sample size of $M=50$ yields an uncertainty $\sim 10 \%$ in the randomized estimate of the trace (Weaver and Courtier, 2001). Because the evaluation of each vector $\mathbf{q}_{i}$ requires an integration of the tangent linear and adjoint of ROMS over the length of each assimilation cycle, it is not feasible to compute an estimate of $\operatorname{Tr}\left(\mathbf{G D G} \mathbf{G}^{T}\right)$ for each assimilation cycle. However, a reduced rank approximation of the preconditioned stabilized representer matrix $\operatorname{Tr}\left(\mathbf{R}^{-1} \mathbf{G D G}^{T}+\mathbf{I}\right)$ can be computed following Gürol et al. (2013) who show that $\left(\mathbf{R}^{-1} \mathbf{G D G}^{T}+\mathbf{I}\right) \simeq \mathbf{V}_{m} \mathbf{T} \mathbf{V}_{m}^{T} \mathbf{G D G}^{T}$ where $\mathbf{V}_{m}$ is the matrix of $m$ Lanczos vectors $(m=15$ is the number of inner-loops) and $\mathbf{T}$ is the $m \times m$ tridiagonal matrix of Lanczos coefficients. In this case $\operatorname{Tr}\left(\mathbf{R}^{-1} \mathbf{G D G} \mathbf{G}^{T}+\mathbf{I}\right) \simeq \operatorname{Tr}\left(\mathbf{V}_{m} \mathbf{T} \mathbf{V}_{m}^{T} \mathbf{G D G}^{T}\right)=\operatorname{Tr}\left(\mathbf{T} \mathbf{V}_{m}^{T} \mathbf{G D G}^{T} \mathbf{V}_{m}\right)=\operatorname{Tr}(\mathbf{T})$ where the last equality is a consequence of the orthonormal property of the Lanczos vectors, $\mathbf{V}_{m}^{T} \mathbf{G D G}^{T} \mathbf{V}_{m}=\mathbf{I}$. While $\operatorname{Tr}(\mathbf{T})$ will be a significant underestimate of $\operatorname{Tr}\left(\mathbf{R}^{-1} \mathbf{G D G} \mathbf{G}^{T}+\mathbf{I}\right)$, they are highly correlated $(r=0.92)$ as shown in Fig. 6a which compares randomized trace 
estimates of $\operatorname{Tr}\left(\mathbf{R}^{-1} \mathbf{G D G}^{T}+\mathbf{I}\right)$ (using $M=50$ ) with $\operatorname{Tr}(\mathbf{T})$ for a selection of 4 D-Var cycles during 1991 (prior to AVISO) and 2004 (post AVISO, MODIS and AMSR-E). The best leastsquares straightline fit is given by $s=9.60 \operatorname{Tr}(\mathbf{T})+4.83 \times 10^{4}$ which can be used to estimate $s=\operatorname{Tr}\left(\mathbf{R}^{-1} \mathbf{G D G} \mathbf{G}^{T}+\mathbf{I}\right)$ for all cycles. Figure $6 \mathrm{~b}$ shows time series of $s$ and $\mathbf{d}^{T} \mathbf{R}^{-1} \mathbf{d}$. If the $a$ priori choice of parameters for $\mathbf{D}$ and $\mathbf{R}$ are correct, then $E\left\{\mathbf{d}^{T} \mathbf{R}^{-1} \mathbf{d}\right\}=\operatorname{Tr}\left(\mathbf{R}^{-1} \mathbf{G D G}^{T}+\mathbf{I}\right)$ and the two time series would be identical. Figure $6 \mathrm{~b}$ shows that this is clearly not the case, which is a further indication that the prior choices for $\mathbf{D}$ and $\mathbf{R}$ are not correct.

Desroziers et al. (2005) also demonstrate how the contributions of individual observations, observation types, or observing platforms to the aforementioned statistics can also be diagnosed by considering appropriate subsets of the dot-products for $\mathbf{d}^{T} \mathbf{d}, \mathbf{d}^{T} \mathbf{d}_{a}^{o}$ and $\mathbf{d}^{T} \mathbf{d}_{b}^{a}$. The corresponding contributions of individual or subsets of observations to GDG $^{T}$ could also be estimated using the randomization method described above, although this would be very costly. Instead, we have used $\mathbf{R}^{-1} \mathbf{F D} \mathbf{F}^{T}$ as an estimate for $\mathbf{R}^{-1} \mathbf{G D G} \mathbf{G}^{T}$ where $\mathbf{F}$ ignores the influence of the ocean dynamics and simply maps $\mathbf{D}$ to the observation points in space each time an observation is available. Figure 6 c shows that $\mathbf{R}^{-1} \mathbf{F D} \mathbf{F}^{T}$ and $\mathbf{R}^{-1} \mathbf{G D G}^{T}$ are highly correlated $(r=0.98)$ for the same sample of randomized trace estimates shown in Fig. 6a, although $\mathbf{R}^{-1} \mathbf{F} \mathbf{D F} \mathbf{F}^{T}$ generally underestimates $\mathbf{R}^{-1} \mathbf{G D G}^{T}$ by $\sim 20 \%$. Assuming that this correlation holds for all cycles and for the sub-traces of $\mathbf{G D G}^{T}$ associated with different observation types, we can use the sub-traces of $\mathbf{F D F}^{T}$ as an approximate surrogate for those of $\mathbf{G D G}^{T}$ as shown in Figs. 6d-6f for temperature, salinity and sea surface height observations. Even allowing for the underestimate of $\operatorname{Tr}\left\{\mathbf{R}^{-1} \mathbf{F D F} \mathbf{F}^{T}\right\}$ compared to $\operatorname{Tr}\left\{\mathbf{R}^{-1} \mathbf{G D G}^{T}\right\}$, Figs. 6d and 6 f suggest that the prior error variances chosen a priori for temperature and sea surface displacement are generally too high. Conversely, the a priori 
choices of error variance for salinity are too low. However, it must be remembered that $\mathbf{d}^{T} \mathbf{d}_{b}^{a}$ does not represent the sum of the true values of the prior error in observation space since $\mathbf{d}$ and $\mathbf{d}_{b}^{a}$ depend on the a priori choice of $\mathbf{D}$ and $\mathbf{R}$. Thus any attempts to modify $\mathbf{D}$ and $\mathbf{R}$ will result in new estimates of $\mathbf{d}$ and $\mathbf{d}_{b}^{a}$ as well. Figure 6e shows that for salinity, $\mathbf{d}^{T} \mathbf{d}_{b}^{a}$ is negative during some cycles which further highlights the sub-optimal nature of the a priori choices of the prior errors for this variable. ${ }^{1}$ An interesting feature of Figs. 6d and 6e is the overall general decline in $\mathbf{d}^{T} \mathbf{d}_{b}^{a}$ as the model fit to the observations of temperature and salinity improves over time.

Figures $6 \mathrm{~g}-6 \mathrm{i}$ show time series of the sub-trace of $\mathbf{R}$ and the corresponding contributions to $\mathbf{d}^{T} \mathbf{d}_{a}^{o}$ for observations of temperature, salinity and sea surface height. For temperature and salinity the a priori combination of measurement error and error of representativeness is generally too low, while for sea surface displacement it is too high.

\section{The Influence of Data Assimilation on the Circula-} tion

To examine the efficacy of the fit of the model to the observations, in this section the impact of 4D-Var on various aspects of the circulation is examined, namely: Sea Surface Temperature (SST), Sea Surface Salinity (SSS), Sea Surface Height (SSH), and Eddy Kinetic Energy (EKE). A forward run of the model subject to the prior forcing and prior open boundary conditions and without data assimilation is used as a benchmark. To gauge geographical

\footnotetext{
${ }^{1}$ While $\mathbf{d d}^{T}=\mathbf{d}_{a}^{o} \mathbf{d}^{T}+\mathbf{d}_{b}^{a} \mathbf{d}^{T}$ is by necessity a positive-definite matrix, there is no such requirement for $\mathbf{d}_{a}^{o} \mathbf{d}^{T}$ and $\mathbf{d}_{b}^{a} \mathbf{d}^{T}$, except when $\mathbf{R}$ and $\mathbf{G D G}^{T}$ are specified correctly.
} 
variations in the impact of $4 \mathrm{D}$-Var on the system, the model domain was subdivided into the four regions illustrated in Fig. 1. The four regions are labelled R1 through R4, and characterize different circulation environments. Regions R1-R3 delineate the different coastal wind regimes identified by Dorman and Winant (1995). R1 spans the Oregon, Washington and Northern California coastal region where the continental shelf is typically narrow and where there is a pronounced seasonal reversal in the alongshore winds leading to upwelling in the summer and downwelling in winter. R2 spans the central California coast where the alongshore winds are generally upwelling favorable year round. Furthermore, R1 and R2 encompass the main features of the CCS surface circulation, such as the equatorward California Current $\sim 500 \mathrm{~km}$ offshore and the near-shore coastal jet, as well as the transition zone that separates the circulation over the shelf from that in the deep ocean (Marchesiello et al., 2003). R3 encompasses the Southern California Bight typically characterized by less seasonal upwelling and by a cyclonic circulation for part of the year (Di Lorenzo, 2003), while R4 encompasses the deep open ocean environment. In each of the four regions the spatial average of SST, SSS, SSH and EKE were computed during each data assimilation cycle for the time varying prior, posterior, and forward run circulation estimates. We will consider first the differences between the 4D-Var posterior and prior circulation estimates for WCRA31, then examine the differences between the WCRA31 4D-Var posterior and forward solutions. Finally the impact of 4D-Var on the EKE and eddy statistics is quantified. In general, the mean adjustments to the open boundary conditions by 4D-Var are small for all variables, therefore the open boundary increments will not be considered further. 


\subsection{Posterior minus prior differences}

Figure 7 shows the mean and standard deviation of the initial condition increments of SST and SSS for all assimilation cycles during WCRA31. Since the posterior and prior estimates are time evolving during 4D-Var, the differences between the time evolving posterior and prior circulation estimates in the four regions of Fig. 1 are summarized in Table 3 for WCRA31. The mean difference between the time evolving posterior and the prior SST is small and slightly negative in all regions indicating that the posterior is $\mathrm{O}\left(0.1^{\circ} \mathrm{C}\right)$ cooler than the prior (Table 3). Figure 7a shows that it generally takes the form of a cold bias which is most pronounced equatorward of Cape Mendocino. The standard deviation of the time evolving differences is approximately $0.25^{\circ} \mathrm{C}$ over the whole domain, although near the coast it is larger (Fig. 7c). There is an apparent change in the character of the SST posterior minus prior differences around 2002 when the prior atmospheric forcing changes to ERA Interim. This is illustrated in Fig. 8a for region R2. An erroneous 6 hours shift in the ERA net radiation flux was inadvertently introduced at this time. However, the 4D-Var analysis procedure was able to compensate for this inconsistency by adjusting the surface heat fluxes, which recall are part of the control vector, leading to a minimal. overall impact on the analyses.

The impact of the AVISO SSH observations on the 4D-Var estimates is very obvious in the time evolving posterior minus prior time series as shown in Fig. 8b for region R2. Table 3 shows that the mean difference is close to zero, with the posterior mean sea-level on average $\mathrm{O}(0.1 \mathrm{~cm})$ lower than the prior. The standard deviation of the differences over the entire $30 \mathrm{yr}$ period is approx $1.5 \mathrm{~cm}$, although the differences after 1992 (when the AVISO 
product came online) are significantly larger than this and in the range $\pm 5 \mathrm{~cm}$ (Fig. 8b).

The mean time evolving posterior minus prior SSS differences are small and indicate that the posterior is slightly fresher, on average, than the prior, and the standard deviation is $\mathrm{O}(0.01)$ or less over the entire domain. The spatial structure of the mean initial condition increments in Fig. 7b confirms this, and shows that the posterior is typically fresher than the prior near the coast. In region R2, the corrections made by $4 \mathrm{D}$-Var to the time evolving prior are generally smaller during the last 20 years of the analysis as shown in Fig. 8c.

Figure $7 \mathrm{~d}$ indicates that the largest increments in salinity are confined to nearshore within the upwelling/downwelling regions poleward of Point Conception.

The differences between the posterior and prior EKE are generally more pronounced during the latter half of the analysis period in regions $\mathrm{R} 1$ and R4, as illustrated in Fig. 8d for region R1. Along the coast (regions R1-R3), Table 3 shows that the posterior is generally more energetic than the prior, while off-shore in deep water (region R4) the opposite is true.

\subsection{Posterior minus forward model differences}

The forward model solution is generally warmer than the posterior in all regions, as illustrated in Fig. 9a for region R2. The posterior SST is representative of the observed SST since SST observations are assimilated into the model. The seasonal cycle is very obvious in Fig. 9a, and low frequency variability is also apparent in the time series and will be discussed in more detail in Part II.

Prior to the introduction of AVISO in 1992, the average posterior and forward SSH fields are very similar as shown in Fig. 9b for region R1. The differences, however, become larger after the introduction of AVISO SSH observations into the assimilation system, and the 
amplitude variations of the posterior SSH estimates are generally lower than those in the forward model. The low frequency variations in SSH will be discussed in Part II.

The posterior estimates are on average fresher than those of the forward model as shown in Fig. 9c for region R4. The number of salinity observations that are assimilated into the model is relatively small compared to the number of temperature measurements (cf Fig. 2), so the lower salinity in the posterior is being driven mainly by adjustments to freshwater fluxes made by 4D-Var. The difference between the net freshwater flux of the posterior and the forward run (not shown) indicates that except for a few areas along the coast, the posterior fluxes are everywhere smaller than those in the forward run (i.e. less posterior evaporation in the subtropics and more posterior precipitation at middle latitudes).

The near-surface EKE time series reveal that the EKE of the posterior is significantly higher than that of the forward model, indicating that the posterior is more energetic as a result of data assimilation. The seasonal amplitude of the EKE variations of the posterior is also significantly larger than that of the forward model as illustrated in Fig. 9d for region R1. This is consistent with the findings of Marchesiello et al (2003) who examined in detail the circulation of the CCS in forward runs of ROMS with different horizontal resolutions. They found that a minimum resolution of approximately $1 / 20^{\circ}$ is required to reliably reproduce the observed EKE and SSH variability. Much of the EKE in their solutions is non-seasonal and geostrophic, and model solutions lower than $1 / 20^{\circ}$ tend to be less energetic. In order to recover the sub-mesoscale variability, much higher resolutions are required (Capet et al, 2008) but this is not the focus of the present study. In the case considered here, however, 4D-Var is able to re-energize the circulation by reconstructing the ocean eddy field from the observations. The impact of 4D-Var on this aspect of the circulation is explored further in 
section 5.4

\subsection{Posterior minus prior surface flux adjustments}

The mean posterior zonal and meridional surface wind stress components from the two sequences of analyses are shown in Figs. 10a-d, and in general the two are very similar. Figures 10e-h show the adjustments that are made to the surface wind stress by $4 \mathrm{D}$-Var (i.e. the difference between the posterior and prior estimates) averaged over all assimilation cycles for WCRA31 and WCRA14. By and large, the patterns of adjustment made to the zonal and meridional components are qualitatively similar during the two sequences of analyses. For example, in both cases the equatorward posterior alongshore wind stress is weaker than in the prior. This is consistent with the findings of Broquet et al. (2011) using the same model with COAMPS forcing but for a shorter time interval (2002-2004) and different satellite observations. Broquet et al. (2011) concluded that the tendency of 4D-Var to weaken the alongshore upwelling favorable winds is most likely associated with systematic model error. Recall that in both WCRA31 and WCRA14, 4D-Var was applied subject to the strong constraint. In general, the meridional wind stress differences between the posterior and the prior are largest during WCRA14 (Fig. 10h), with 4D-Var making the largest corrections near $128^{\circ} \mathrm{W}, 38^{\circ} \mathrm{N}$, a feature also present during WCRA31 but weaker (Fig. 10f). A region of positive zonal wind stress adjustments between $35^{\circ} \mathrm{N}$ and $45^{\circ} \mathrm{N}$ within $300-400 \mathrm{~km}$ of the coast is present in both sequences of analyses (Figs. 10e and 10g) with largest values near the coast between Cape Mendocino and San Francisco Bay, although it covers a geographically broader area in WCRA31 extending all the way to the southern boundary. In general, the adjustments made to the surface wind stress by the $4 \mathrm{D}$-Var procedure are $\sim 5-10 \%$ of the 
mean.

The mean posterior total surface heat fluxes for WCRA31 and WCRA14 are shown in Fig. 11 averaged over all cycles. Near the coast the mean heat fluxes are similar, however offshore the fluxes from WCRA14 are significantly lower than in WCRA31. This is also reflected in the posterior minus prior heat flux differences. Near the coast and in the upwelling region, 4D-Var makes similar adjustments to the total heat flux in both sequences of analyses. However, offshore the 4D-Var heat flux corrections are predominantly negative (positive) in WCRA31 (WCRA14). Near the coast the 4D-Var flux adjustments are $10 \%$ of the mean, while offshore the adjustments are the same order of magnitude as the mean.

The root mean square (rms) wind stress and heat flux differences between the posterior and the prior averaged over the whole model domain for all years are summarized in Table 4. While the true winds and heat fluxes are not known, Table 4 compares the rms of the 4D-Var surface flux adjustments to the rms difference between various other commonly used ocean forcing products for this region, including an estimate of surface wind stress based on QuikScat. Table 4 shows that the rms of the 4D-Var adjustments in both WCRA31 and WCRA14 are generally small compared to the rms differences between different atmospheric products, indicating that the 4D-Var adjustments are not unreasonable.

The mean posterior total surface freshwater fluxes (evaporation minus precipitation) for the two sequences of analyses are shown in Fig. 12, along with the posterior minus prior flux differences, averaged over all assimilation cycles in each case. In general the mean freshwater fluxes and 4D-Var flux adjustments are qualitatively and quantitatively similar, although the adjustments in WCRA14 contain more small scale features than those in WCRA31 in the central part of the domain, which is associated with the higher resolution of the freshwater 
flux prior used in WCRA14 from the inner-most grid of the COAMPS nested configuration (Doyle et al., 2009). The freshwater flux adjustments made by 4 D-Var are $\sim 5-10 \%$ of the mean. Estimates of the rms differences in surface freshwater fluxes are not shown in Table 4 since they are highly uncertain regardless of the source of the estimate.

\subsection{EKE and a census of eddies}

Eddies are an important component of the circulation in the CCS since they form a bridge between the shelf and deep ocean, and they are known to be important for primary production (Falkowski et al, 1991; McGillicuddy et al, 1998). As discussed in sections 5.1 and 5.2, data assimilation increases the EKE of the 4D-Var circulation estimates over much of the model domain. This is further illustrated in Fig. 13 which shows the difference between the 30 year mean surface eddy kinetic energy (EKE) computed from WCRA31 and the forward model without data assimilation. Figure 13 shows that there is a region of elevated EKE offshore and downstream of Cape Mendicino in the same general area as that identified in satellite altimeter observations (Kelly et al, 1998; Strub and James, 2000; Stegmann and Schwing, 2007). This suggests that 4D-Var is able to recover the surface EKE signature from the satellite observations, despite the relatively low model resolution. EKE is elevated in the same region in WCRA14 compared to a forward model run forced with COAMPS (not shown).

It is instructive to compare the model surface EKE with estimates derived from observations. With this in mind, the space-time average surface EKE was computed in the region $36^{\circ} \mathrm{N}-40^{\circ} \mathrm{N}, 124^{\circ} \mathrm{W}-130^{\circ} \mathrm{W}$, indicated in Fig. 13, which encompasses the region of maximum EKE in both the model and observational estimates. Two observational estimates were 
computed: one from AVISO SSH based on surface geostrophic velocities (1992-2010), and a second from surface drifter observations (1987-2014). The surface drifter observations from www.aoml.noaa.gov/envids were sorted in to $0.5^{\circ} \times 0.5^{\circ}$ bins, and processed as described by Veneziani et al. (2009a). The mean surface EKE in WCRA31 (WCRA14) is $95 \pm 35 \mathrm{~cm}^{2} \mathrm{~s}^{-2}$ $\left(96 \pm 34 \mathrm{~cm}^{2} \mathrm{~s}^{-2}\right)$ compared to $85 \pm 23 \mathrm{~cm}^{2} \mathrm{~s}^{-2}\left(86 \pm 27 \mathrm{~cm}^{2} \mathrm{~s}^{-2}\right)$ in the forward model without data assimilation. The mean EKE estimated from AVISO is $113 \pm 47 \mathrm{~cm}^{2} \mathrm{~s}^{-2}$ while that from the drifters is $235 \pm 178 \mathrm{~cm}^{2} \mathrm{~s}^{-2}$. 4D-Var increases the surface EKE by $\sim 10 \%$ compared to the forward model without data assimilation, although both analyses are lower than the AVISO estimates, and less than half that from drifters. However, the model EKE signature in the 4D-Var estimates extends well below the surface indicating that the vertical structure of the eddies is also recovered. For example, data assimilation increases the depth averaged EKE over the upper $500 \mathrm{~m}$ by $\sim 50 \%$ compared to the forward model, indicating that 4D-Var is effective at propagating or projecting energy down through the water column.

To further illustrate, Fig. 14 shows Hovmoller diagrams of the difference in depth averaged EKE over the upper $500 \mathrm{~m}$ between WCRA31 and the forward model (no data assimilation), and averaged between Cape Blanco $\left(43^{\circ} \mathrm{N}\right)$ and Point Conception $\left(34^{\circ} \mathrm{N}\right)$ as a function of offshore distance. Adjacent to the coast, depth averaged EKE in WCRA31 and the forward model are similar (recall that SSH observations are not assimilated within $50 \mathrm{~km}$ of the coast), while $50-500 \mathrm{~km}$ offshore the depth averaged EKE of WCRA31 is elevated compared to the forward model. Elevated westward propagation of the EKE is apparent in WCRA31 in agreement with observation (Kelly et al, 1998; Strub and James, 2000; Stegmann and Schwing, 2007), and consistent with the generaly accepted idea of eddy formation via baroclinic instability within the CCS and westward propagation of eddies as 
Rossby waves (Barth, 1994; Marchesiello et al., 2003). Figure 14 suggests that the 4D-Var analyses are able to more successfully capture this process.

To shed more light on the nature of the elevated EKE in the 4D-Var analyses, individual eddies present in the circulation estimates were identified using the Okubo-Weiss parameter $W$ (Weiss, 1991) which is defined as $W=\left(u_{x}-v_{y}\right)^{2}+\left(v_{x}+u_{y}\right)^{2}-\left(v_{x}-u_{y}\right)^{2}$, where subscripts denote partial derivatives with respect to the indicated independent variable. As discussed by Chelton et al. (2007), eddy cores are characterized by regions where $W<0$. The Okubo-Weiss parameter was computed here using the 8-day average velocity components corresponding to each assimilation cycle ensuring that the circulations are in dynamic balance. Each field of $W$ was smoothed using eight applications of a 2nd order Shapiro filter, and values of $W$ within three grid points of the coast were disgarded to minimize the possibility of miss-identifying eddy cores associated with the computation of derivatives on the ROMS staggered grid near land-sea boundaries. In addition, $W$ was not computed in the sponge layers adjacent to each open boundary. Eddy cores were identified as regions where $W$ was less than twice the mean of all negative values of $W$ over the model domain, which has the effect of isolating the most intense regions of $W<0$ which are most likely associated with eddy cores, although false alarms are possible (Chaigneau et al, 2009; Kurian et al, 2011; Davis and Di Lorenzo, 2015). The eddies identified in this way were then counted, and the number of eddies found during each 8-day cycle recorded.

Figure 15a shows a time series of the total number of eddies identified in both WCRA31 and the forward model without data assimilation. Figure 15a shows that on average there are $\sim 50 \%$ more eddies present in WCRA31 than in the forward model, consistent with the elevated levels EKE in the former. In both cases, the number of eddies varies considerably 
from year to year (in agreement with other studies, such as Stegmann and Schwing, 2007; Davis and Di Lorenzo, 2015), and exhibits a pronounced seasonal cycle, with the maximum eddy count occurring during spring at the start of the upwelling season. Similar results were obtained for WCRA14 (not shown). In WCRA31, Fig. 15a shows that the difference in the number of eddies is particularly pronounced during the period when AVISO SSH observations were assimilated into the model beginning in 1992.

The influence of 4D-Var on energizing the circulation via eddy generation was further illustrated by performing a second run of the forward model initialized from the 4D-Var analysis on 17 Feb. 1995, then integrated forward in time without data assimilation. A time series of the total eddy count for this case is also shown in Fig. 15a. Following the abrupt end of data assimilation, the number of eddies decreases within 40-60 days to the same level as the original forward model run, showing that the spin-down of the eddies in the model is quite rapid if they are not maintained by 4D-Var. A time series of the EKE from the same spin-down calculation displays a similar behaviour (not shown).

The total eddy counts in regions R1 and R4 exhibit a pronounced seasonal cycle which is less well defined in R2 and R3. A further analysis of the vorticity field associated with each eddy core reveals regional variations in the number of cyclonic and anticyclonic eddies. In regions $\mathrm{R} 1, \mathrm{R} 3$ and $\mathrm{R} 4$, there are generally more cyclonic eddies than anticyclonic eddies (not shown), particularly in the forward model, in general agreement with observations (Stegmann and Schwing, 2007).

The eddies can be further classified as geostrophic or ageostrophic. Geostrophic eddies were identified using SSH $\zeta$ to compute the geostrophic approximation of $W=4\left(u_{g_{x}}^{2}+v_{g_{x}} u_{g_{y}}\right)$ following Chelton et al. (2007), where $u_{g}=-(g / f) \zeta_{y}$ and $v_{g}=(g / f) \zeta_{x}$. Eddies with 
a significant ageostrophic component were identified as those which have no discernable geostrophic signature. These are typically eddies that have a weak geostrophic core which falls below the detection threshold for the spatially smoothed $W$, but surrounded by an ageostrophic halo. The nature of the dynamical balance within the halo region is not known at this time, and is beyond the scope of this study, but could include advection of momemtum (e.g. Penven et al., 2014) and wind influences (e.g. Sudre et al., 2013). Figure 15b shows time series of the ratio of the number ageostrophic eddies to the number of geostrophic eddies identified in WCRA31 and the forward model, and indicates that in WCRA31 40\% of the eddies are dominated by ageostrophic circulations compared to $\sim 28 \%$ in the forward model. Similar ratios are present in WCRA14 (not shown). Kelly et al. (1998) argued that the level of EKE based on SSH observations may be lower than that derived from drifter data because of the contribution of ageostrophic circulations which are undetectable in the altimeter observations, an idea confirmed in other regions (e.g. Penven et al., 2014). In the forward runs, $73 \%$ of the eddies with significant ageostrophic circulations are located near the coast in regions R1-R3 compared to $56 \%$ in the 4D-Var analyses. This is consistent with the elevated ageostrophic EKE documented by Marchesiello et al. (2003) near shore in other non-data assimilative configurations of ROMS for the CCS.

Figure 15c shows the probability density function (PDF) of the diameter of the eddy cores based on estimates of the circumference of each eddy. This calculation assumes that each eddy is circular, which of course is not the case, but nevertheless the equivalent eddy core diameter serves as a useful reference. Figure 15c shows that the mode of the eddy core diameter is $\sim 60 \mathrm{~km}$ in agreement with the study by Kurian et al. (2011), although on the whole WCRA31 (and WCRA14, not shown) tends to favor somewhat smaller eddy cores 
than the forward model. Figure 15d shows the PDF of eddy core diameter for geostrophic and ageostrophic eddies for WCRA31, and that from the forward run is qualitatively similar (not shown). The mode of the eddy core diameter for both the geostrophic and ageostrophic eddies is also $\sim 60 \mathrm{~km}$. However, in the case of the geostrophic eddies, the PDF is also clearly elevated at scales of the first baroclinic mode Rossby radius of deformation which is $\sim 20-35 \mathrm{~km}$ in the CCS (Chelton et al., 1998). It is important to recall that the fields of $W$ were filtered prior to identifying the eddies. This smoothing removes any features in $W$ with a scale of twice the model grid spacing. In addition, the diameters in Fig. 15d relate only the eddy cores, meaning that the eddies themselves will have diameters larger than this. Therefore, the elevated probability density of the geostrophic eddies at diameters $\sim 20-35 \mathrm{~km}$ compared to the ageostrophic eddies is a real effect. The PDF of eddy diameter for WCRA14 is similar to that for WCRA31.

The dominant eddy diameters identified here are somewhat smaller than the mean eddy size $\sim 165 \mathrm{~km}$ identified in SSH observations by Stegmann and Sshwing (2007). However, their study was limited to circular, geostrophic eddies on a $1 / 3^{\circ}$ grid with life spans longer than 35 days, so their analysis will exclude smaller short-lived eddies as well as eddies with significant ageostrophic circulations.

\subsection{Departures from the observations}

To explore the veracity of the subsurface circulation, the 4D-Var posterior circulation estimates were compared to vertical temperature and salinity profiles collected as part of the California Cooperative Oceanic Fisheries Investigation (CalCOFI). The data used here are from the period March 1990 to July 2007. There are typically cruises four times a year, 
mainly off southern California as shown in Fig. 1. It is traditional to compare posterior estimates to independent observations that have not been assimilated into the model. However, some of the CalCOFI cruise data used here are included in the EN3 data set, so the 4D-Var and CalCOFI data set comparisons are not truly independent. However, Schroeder et al. (2014) present a comparison of the WCRA31 analyses with independent observations of the CCS off the central California coast collected at a mooring near Monterey Bay and by the NOAA National Marine Fisheries Service, and conclude that the 4D-Var analyses yield reliable estimates of temperature and salinity despite the presence of some overall biases.

A comparison was made at each CalCOFI station between the in situ observations and the corresponding profiles of salinity and potential temperature from the 4D-Var posterior circulation estimates. Figure 16a summarizes the statistics of the posterior minus observation differences for temperature and salinity averaged over all of the CalCOFI survey locations for the period Jan. 1990 - July 2007 for WCRA31. The results for WCRA14 are similar and are not shown. The corresponding analysis for the forward run without data assimilation is summarized in Fig. 16b.

Figure $16 \mathrm{~b}$ shows that in the absence of data assimilation, the model exhibits a warm temperature bias $\sim 0.7^{\circ} \mathrm{C}$ above $150 \mathrm{~m}$ and a cold bias $\sim-0.2^{\circ} \mathrm{C}$ between 150 and $450 \mathrm{~m}$. Following data assimilation, the bias is close to zero in the upper $50 \mathrm{~m}$, and the warm bias between 50 and $150 \mathrm{~m}$ has been reduced to $\sim 0.2^{\circ} \mathrm{C}$. Below $150 \mathrm{~m}$ 4D-Var has reduced the cold bias slightly. The forward model has a positive salinity bias between $\sim 50$ and $150 \mathrm{~m}$ but matches the mean of the observations very well below this (Fig. 16b). In the upper $50 \mathrm{~m}$ or so of the water column the forward model salinity agrees quite well with the observations. Data assimilation substantially reduces the subsurface postive salinity bias 
(Fig. 16a), although it introduces a negative bias in the upper $75 \mathrm{~m}$ of the water column.

In terms of the variability, Fig. $16 \mathrm{~b}$ reveals that the forward model under-estimates the observed subsurface temperature variability above $\sim 175 \mathrm{~m}$, while the agreement between the 4D-Var estimates and the observations in Fig. 16a is generally very good. Both the forward model and the 4D-Var circulation estimates significantly over estimate the variability in salinity in the upper $125 \mathrm{~m}$.

\section{Summary and Discussion}

Two sequences of historical analyses of the California Current circulation have been computed using ROMS 4D-Var. One sequence spans the period 1980-2010 while the second sequence spans the shorter period 1999-2012. The two sequences differ only in the prior ocean surface forcing fields used during the 4D-Var analysis cycles. On the whole, the 4DVar system performs well as evidenced by the significant decrease in the cost function during each data assimilation cycle. The tangent linear assumption employed by 4D-Var is generally valid throughout the two periods considered as indicated by the generally good agreement between $\mathcal{J}$ and $\mathcal{J}_{N L}$ although nonlinearity seems to play more of a role during WCRA14, perhaps due to the higher resolution surface forcing. Further evidence for the well behaved nature of the 4D-Var cycles is the very small percentage of observations that were rejected by the background quality control check. An examination of the statistics of the innovations reveals that there is scope for improvement in the a priori choice of parameters for the prior error and observation error covariance matrices. This is not unexpected since the correct specification of a time evolving multivariate covariance matrix is a tall order. Nonetheless, 
the innovation statistics point to ways in which specification of the covariance model variances can be improved by tuning the error variances following the iterative process outlined in Desroziers et al. (2005) and Desroziers and Ivanov (2001).

Data assimilation has a significant influence on the time evolving circulation as evidenced by the differences between the posterior estimates and those from a model without data assimilation, as well as the differences between the prior and posterior fields. One notable characteristic of the posterior circulation estimates is that they are more energetic than the model run without data assimilation, as evidenced by the EKE.

Further investigation reveals that both sequences of analyses more faithfully capture the region of elevated EKE observed offshore and downstream of Cape Mendocino, with offshore propagation of EKE by eddies consistent with baroclinic instability of the California Current and Rossby wave propagation. However, both analyses consistently under estimate the level of EKE based on observational estimates, most likely because of the relatively low model resolution used here. Nevertheless, 4D-Var energizes the circulation, and there are generally more eddies present during the 4D-Var analyses than in runs of the model without data assimilation. However, the number of eddies decreases within a month or so if data assimilation is not maintained. In addition, the 4D-Var analyses capture a higher fraction of eddies with a significant ageostrophic component, often in the form of an ageostrophic halo surrounding a very weak geostrophic core. The nature of the ageostrophic circulations and halos, with diameters that peak near $60 \mathrm{~km}$, is unclear and deserves further attention, athough they are unlikely to be an artifact of 4D-Var since they are present in the forward model runs also. The PDF of eddy core diameter during 4D-Var indicates that geostrophic eddy energy has a tendency to accumulate at scales of the first baroclinic radius of deformation. As noted 
earlier, the elevated levels of EKE and number of eddies in the 4D-Var analyses compared to forward model runs is likely to have important implications for primary productivity in ecosystem models driven by the analysis circulation fields.

Data assimilation was found to significantly improve some aspects of the subsurface circulation when compared to a subset of the CalCOFI hydrographic observations. In particular the temperature and salinity biases were reduced, and the 4D-Var analyses more faithfully capture the subsurface temperature variability. However, data assimilation is unable to correct for the over estimation of upper ocean salinity variance in the forward model.

The version of ROMS 4D-Var that was used for the calculations described here has a number of shortcomings and limitations which are likely to impact the circulation estimates to some degree. However, the latest release of the 4D-Var code has more utility and a second sequence of calculations are planned using the improved system. Specific changes and improvements to the calculations will include: (1) inhomogeneous covariance models that allow the a priori correlation lengths scales to vary spatially across the domain. This is expected to have a significant impact near the coast where the covariance functions are likely to be particularly inhomogeneous; (2) the use of temporal correlation functions for the prior error. It is anticipated that this will allow a more efficient use of along-track satellite altimeter observations in place of the gridded products that are currently used; and (3) the use of a multivariate balance operator which includes an improved method for estimating the depth of the surface mixed layer where the balancing of temperature and salinity is disabled. Additional changes that will be made during the second sequence of 4D-Var analyses will include: (a) explicitly allowing for the correlation between errors in the prior and observations during the period of overlap between the current cycle and the 
previous cycle; (b) refinements to the background error covariance and observation error covariance model parameters based on the analyses of the innovations in section 4.2; and (c) correction of the 6 hour offset in the specification of the ERA Interim net surface radiation fields. As experience in NWP has shown, it is anticipated that further improvements in the CCS circulation analyses can be expected by future iterative refinements of the analysis system resulting from rigorous quantitative analysis of the 4D-Var circulation estimates by the oceanographic community.

Both sequences of analyses are available to the oceanographic community from http://oceanmodeling.ucsc.edu/ and represent a valuable community resource that can be used for a wide range of applications. Some recent applications by NOAA include modeling the population of juvenile Salmon (Schroeder et al., 2014), larval transport studies (Bjorkstedt, personal communication), and understanding whale migration patterns along the U.S. west coast (Forney and Becker, personal communication). Analysis of the circulation variability captured by the 4D-Var analyses is ongoing (e.g. Jacox et al., 2014, 2015), and Part II by Crawford et al. (2015) is dedicated to analysis of the CCS circulation variability on interannual-to-decadal timescales.

\section{Acknowledgements}

This research was supported by a grant from the National Science Foundation (OCE 1061434). The altimeter products were produced by Ssalto/Duacs and distributed by AVISO, with support from CNES (http://www.aviso.altimetry.fr/duacs/). We are also grateful to the three anonymous reviewers who helped to improve the manuscript content. 


\section{References}

Andersson, E. and H. Järvinen, 1999: Variational quality control. Q. J. R. Meteorol. Soc., 125, 679-722.

Andersson, E., M. Fisher, R. Munro and A. McNally, 2000: Diagnosis of background errors for radiances and other observable quantities in a variational data assimilation scheme and the explanation of a case of poor convergence. Q. J R. Meteorol. Soc., 126, $1455-1472$.

Atlas, R., R. N. Hoffman, J. Ardizzone, S. M. Leidner, J. C. Jusem, D. K. Smith, D. Gombos, 2011: A cross-calibrated, multiplatform ocean surface wind velocity product for meteorological and oceanographic applications. Bull. Amer. Meteor. Soc., 92, 157-174. doi: 10.1175/2010BAMS2946.1.

Balmaseda, M. A., A. Vidard and D.L.T. Anderson, 2008: The ECMWF Ocean Analysis System: ORA-S3. Mon. Wea. Rev., 136, 3018-3034.

Bannerjee, S., Carlin, B.P. and A.E. Gelfand, 2004: Hierarchical Modeling and Analysis for Spatial Data. Monographs on Statistics and Applied Probability, 101, Chapman Hall/CRC Press.

Barth, J.A., 1994: Short-wavelength instabilities on coastal jets and fronts. J. Geophys. Res., 99, 16,095-16,115.

Broquet, G., C.A. Edwards, A.M. Moore, B.S. Powell, M. Veneziani and J.D. Doyle, 2009: Application of 4D-variational data assimilation to the California Current System. Dyn. Atmos. Oceans, 48, 69-91.

Broquet, G., A.M. Moore, H.G. Arango, and C.A. Edwards, 2011: Corrections to ocean 
surface forcing in the California Current System using 4D-variational data assimilation. Ocean Modelling, 36, 116-132.

Capet, X., P. Marchesiello and J.C. McWilliams, 2004: Upwelling response to coastal wind profiles. Geophys. Res. Letts., 31, L13311, doi:10.1029/2004GL020123.

Capet, X., J.C. McWilliams, M.J. Molemaker and A.F. Shchepetkin, 2008: Mesoscale to submesoscale transition in the California Current System. Part I: Flow, structure, eddy flux and observational tests. J. Phys. Oceanogr., 38, 29-43.

Carton, J.A. and B.S. Giese,2008.: A reanalysis of ocean climate using simple ocean data assimilation (SODA). Mon. Wea. Rev., 136, 2999-3017.

Castelao, R.M. and J.A. Barth, 2006: The relative importance of wind strength and alongshelf bathymetric variations on the separation of a coastal upwelling jet. J. Phys. Oceanogr., 36, 412-425.

Chaigneau, A., G. Eldin and B. Dewitte, 2009: Eddy activity in the four major upwelling systems from satellite altimetry (1992-2007). Progress in Oceanography, 83, 117-123.

Chao, Y., Z. Li, J. Farrara, J.C. McWilliams, J. Belllingham, X. Capet, F. Chavez, J.-K. Choi, R. Davis, J. Doyle, D.M. Fratantoni, P. Li, P. Marchesiello, M.A. Moline, J. Paduan and S. Ramp, 2009: Development, implementation and evaluation of a data assimilative ocean forecasting system off the central California coast. Deep Sea Res., 56, $100-126$.

Chapman, D.C., 1985: Numerical treatment of cross-shelf open boundaries in a barotropic coastal ocean model. J. Phys. Oceanogr., 15, 1060-1075.

Checkley, D.M. and J.A. Barth, 2009: Patterns and process in the California Current system. Prog. Oceanogr., 83, 49-64. 
Courtier, P., J.-N. Thépaut and A. Hollingsworth, 1994: A strategy for operational implemenation of 4D-Var using an incremental approach. Q. J. R. Meteorol. Soc., 120, $1367-1388$.

Chelton, D.B., R.A. DeSzoeke, M.G. Schlax, K. El Naggar and N. Siwertz, 1998: Geographical variability of the first baroclinic Rossby radius of deformation. J. Phys. Oceanogr., 28, 433-460.

Crawford, W., A.M. Moore, M.G. Jacox, E. Neveu, J. Fiechter and C.A. Edwards, 2015: An Historical analysis of the California Current using ROMS 4D-Var. Part II: Climate Variability. Submitted.

Davis, A. and E. Di Lorenzo, 2015: Interannual forcing mechanisms of California Current transports II: Mesoscale eddies. Deep Sea Res. II, 112, 31-41.

Dee, D.P., S. M. Uppala, A. J. Simmons, P. Berrisford, P. Poli, S. Kobayashi, U. Andrae, M. A. Balmaseda, G. Balsamo, P. Bauer, P. Bechtold, A. C. M. Beljaars, L. van de Berg, J. Bidlot, N. Bormann, C. Delsol, R. Dragani, M. Fuentes, A. J. Geer, L. Haimberger, S. B. Healy, H. Hersbach, E. V. Hólm, L. Isaksen, P. Källberg, M. Köhler, M. Matricardi, A. P. McNally, B. M. Monge-Sanz, J.-J. Morcrette, B.-K. Park, C. Peubey, P. de Rosnay, C. Tavolato, J.-N. Thépaut and F. Vitart, 2011: The ERA-Interim reanalysis: configuration and performance of the data assimilation system, Q.J.R. Meteorol. Soc., 137, 553-597, doi: 10.1002/qj.828.

Derber, J. and A. Rosati, 1989: A global oceanic data assimilation system. J. Phys. Oceanogr., 19, 1333-1347.

Desroziers, G., L. Berre, B. Chapnik and P. Poli, 2005: Diagnosis of observation, background and analysis-error statistics in observation space. Q. J. R. Meteorol. Soc., 131, 3385- 
3396.

Desroziers, G. and S. Ivanov, 2001: Diagnosis and adaptive tuning of observation error covariance parameters in a variational assimilation/ Q. J. Roy. Meteorol. Soc., 127, 1433-1452.

Dibarboure, G., M.-I. Pujol, F. Briol, P. Y. Le Traon, G. Larnicol, N. Picot, F. Mertz, and M. Ablain, 2011: Jason-2 in DUACS: Updated system description, first tandem results and impact on processing and products. Mar. Geod., 34, (3-4), 214-241.

DiLorenzo, E., 2003: Seasonal dynamics of the surface circulation in the Southern California Current system. Deep Sea Res. II, 50, 2371-2388.

DiLorenzo, E., J. Fiechter, N. Schneider, A. Bracco, A.J. Miller, P.J.. Franks, S. Brograd, A.M. Moore, A.C. Thomas, W. Crawford, A. Peña and A. Hermann, 2009: Nutrient and salnity decadal variations in the central and eastern North Pacific. Geophys. Res. Letts., 36, L14601, doi:10.1029/2009GL038261.

Dorman, C.E. and C.D. Winant, 1995: Buoy observations of the atmosphere along the west coast of the United States, 1981-1990. J. Geophys. Res., 100, 16,029-16,044.

Doyle, J.D., Q. Jiang, Y. Chao and J. Farrara, 2009: High-resolution atmospheric modeling over the Monterey Bay during AOSN II. Deep Sea Res. II, 56, 87-99.

Edwards, C.A., A.M. Moore, I. Hoteit and B.D. Cornuelle, 2015: Regional ocean data assimilation. Ann. Rev. Mar. Sci., 7, 6.1-6.22.

Enriquez, A.G. and C.A. Friehe, 1995: Effects of wind stress and wind stress curl variability on coastal upwelling. J. Phys. Oceanogr., 25, 1651-1671.

Fairall, C.W., E.F. Bradley, J.S. Godfrey, G.A. Wick, J.B. Edson and G.S. Young, 1996a: Cool-skin and warm layer effects on the sea surface temperature. J. Geophys. Res., 
101, 1295-1308.

Fairall, C.W., E.F. Bradley, D.P. Rogers, J.B. Edson and G.S. Young, 1996b: Bulk parameterization of air-sea fluxes for tropical ocean global atmosphere Coupled-Ocean Atmosphere Response Experiment. J. Geophys. Res., 101, 3747-3764.

Falkowski, P., D. Ziemann, Z. Kolber and P.Bienfang, 1991: Role of eddy pumping in enhancing primary productivity production in the ocean. Nature, 352, 55-58.

Flather, R.A., 1976: A tidal model of the northwest European continental shelf. Memoires de la Societe Royale des Sciences de Liege 6 (10), 141-164.

Gratton, S., and J.Tshimanga, 2009: An observation-space formulation of variational assimilation using a restricted preconditioned conjugate gradient algorithm. Q. J. R. Meteorol. Soc., 135, 1573-1585.

Gürol, S., A.T. Weaver, A.M. Moore, A. Piacentini, H.G. Arango and S. Gratton, 2013: B-preconditioned minimization algorithms for variational data assimilation with the dual formulation. Q. J. Roy. Meteorol. Soc., doi:10.1002/qj.2150.

Hickey, B.M., 1979: The California Current System: hypotheses and facts. Progress in Oceanography, 8, 191-279.

Hickey, B.M., 1998: Coastal oceanography of western North America from the tip of Baja, California to Vancouver Island. The Sea, 11, 345-393, Eds. A.R. Robinson and K.H. Brink, John Wiley and Sons.

Hollingsworth, A., D.B. Shaw,P. Lnnberg, L. Illari, K. Arpe, K. and A Simmons, 1986: Monitoring of observation and analysis quality by data assimilation systems. Mon Wea. Rev., 114, 861-879.

Ingleby, B. and M. Huddleston, 2007: Quality control of ocean temperature and salinity 
profiles - historical and real-time data. J. Mar. Systems, 65, 158-175.

Jacox, M.G., A.M. Moore, C.A. Edwards and J. Fiechter, 2014: Spatially resolved upwelling in the California Current system and its connections to climate variability. Geophys. Res. Letts., 41, 3189-3196, doi:10.1002/2014GL059589.

Jacox, M.G., J. Fiechter, A.M. Moore and C.A. Edwards, 2015: El Niño and the California Current Coastal Upwelling Response. J. Geophys. Res., In press.

Järvinen, H. and P. Undén, 1997: Observation screening and first guess quality control in the ECMWF 3D-Var data assimilation system. ECMWF Tech. Memo, 236, EMCWF, Shinfield Park, Reading, U.K.

Källberg, P., A. Simmons, S. Uppala and M. Fuentest, 2004: The ERA-40 Archive. ERA-40 Project Report Series No. 17.

Kelly, K.A., R.C. Beardsley, R. Limeburner, K.H. Brink, J.D Paduan and T.K. Chereskin, 1998: Variability of the near-surface eddy kinetic energy in California Current based on altimetric, drifter, and moored current data. J. Geophys. Res., 103, 13,067-13,083.

Kurian, J., F. Colas, X. Capet, J.C. McWilliams and D.B. Chelton, 2011: Eddy properties in the California Current System. J. Geophys. Res., 16, C08027, doi:10.1029/2010JC006895.

Kurapov, A.L., G.D. Egbert, J.S. Allen and R.N. Miller, 2009: Representer-based analyses in the coastal upwelling system. Dyn. Atmos. Ocean., 48, 198-218.

Kurapov A.L., D. Foley, P.T. Strub, G.D. Egbert, and J.S. Allen, 2011: Variational assimilation of satellite observations in a coastal ocean model off Oregon. J. Geophys. Res., 116, C05006.

Lawless, A.S., S. Gratton, and N.K. Nichols, 2005: Approximate iterative methods for variational data assimilation. Int. J. Numer. Meth. Fl., 1, 1-6. 
Le Dimet, F.-X. and O. Talagrand, 1986: Variational algorithms for analysis and assimilation of meteorological observations. Tellus, 38A, 97-110.

Levitus, S., J.I. Antonov, T.P. Boyer, R.A. Locarnini, H.E. Garcia, and A.V. Mishonov, 2009: Global ocean heat content 1955-2008 in light of recently revealed instrumentation problems. Geophys. Res. Letts., 36, L07608, doi:10.1029/2008GL037155.

Lewis, J. and Derber, J., 1985: The use of adjoint equations to solve a variational adjustment problem with advective constraints. Tellus, 37, 309-327.

Li, Z., Y. Chao, J.C. McWilliams and K. Ide, 2008: A three-dimensional variational data assimilation scheme for the regional ocean modeling system. J. Atmos. Ocean. Tech., 25, 2074-2090.

Liu, W.T., K.B. Katsaros and J.A. Businger, 1979: Bulk parameterization of the air-sea exchange of heat and water vapor including the molecular constraints at the interface. J. Atmos. Sci., 36, 1722-1735.

Lorenc, A.C., and P. Hammon, 1988: Objective quality control of observations using Bayesian methods. Theory, and a practical implementation. Q. J. R. Meteorol. Soc., 114, 515543.

Lynn, R.J. and S.J. Bograd, 2002: Dynamic evolution of the 1997-1999 El Niño-La Niña cycle in the southern California Current System. Prog. Oceanogr., 54, 59-75.

Mantua, N.J., S.R. Hare, Y. Zhang, J.M. Wallace and R.C. Francis, 1997: A Pacific interdecadal climate oscillation with impacts on salmon production. Bull. Amer. Met. Soc., 78, 1069-1079.

Marchesiello, P., J.C. McWilliams and A. Shchepetkin, 2003: Equilibrium structure and dynamics of the California Current System. J. Phys. Oceanogr., 33, 753-783. 
Marchesiello, P., L. Debreu and X. Couvelard, 2009: Spurious diapycnal mixing in terrainfollowing coordinate models: The problem and a solution. Ocean Modelling, 26, 156169.

Matthews, D., B. Powell, and R.F. Milliff, 2011: Dominant spatial variability scales from observations around the Hawaiian Island. Deep Sea Res. I, 58, 979-987.

McGillicuddy, D. J., Jr., A. R. Robinson, D. A. Siegel, H. W. Jannasch, R. Johnson, T. D. Dickey, J. McNeil, A. F. Michaels, and A. H. Knap 1998: Influence of mesoscale eddies on new production in the Sargasso Sea, Nature, 394, 263-266.

Milliff, R.F., P. Niiler, J. Morzel, A. Sybrandy, D. Nychka, and W. Large, 2033.: Mesoscale correlation length scales from NSCAT and Minimet surface wind retrievals in the Labrador Sea. J. Atmos. Oceanic Technol., 20, 513-533.

Mogensen, K., M.A. Balmaseda and A.T. Weaver, 2012: The NEMOVAR ocean data assimilation system as implemented in the ECMWF ocean analysis for system 4. ECMWF Technical Memo., 668, 61pp.

Moore, A.M., H.G. Arango, G. Broquet, B.S. Powell, J. Zavala-Garay and A.T. Weaver, 2011a: The Regional Ocean Modeling System (ROMS) 4-dimensional variational data assimilation systems. Part I: System overview and formulation. Progress in Oceanography, 91, 34-49.

Moore, A.M., H.G. Arango, G. Broquet, C. Edwards, M. Veneziani, B. Powell. D. Foley, J. Doyle, D. Costa and P. Robinson, 2011b: The Regional Ocean Modeling System (ROMS) 4-dimensional variational data assimilation systems. Part II: Performance and application to the California Current System. Progress in Oceanography, 91, 5073. 
Moore, A.M., H.G. Arango, G. Broquet, C. Edwards, M. Veneziani, B. Powell. D. Foley, J. Doyle, D. Costa and P. Robinson, 2011c: The Regional Ocean Modeling System (ROMS) 4-dimensional variational data assimilation systems. Part III: Observation impact and observation sensitivity in the California Current System. Progress in Oceanography, 91, 74-94.

Moore, A.M., C. Edwards, J. Fiechter, P. Drake, H.G. Arango, E. Neveu, S. Gürol and A.T. Weaver, 2013: A Prototype for an Operational Regional Ocean Data Assimilation System. Chapter 14 In "Data Assimilation for Atmospheric, Oceanic and Hydrological Applications, Vol II", Liang Xu and Seon Park, Eds. Springer, pp345-366.

Ngodock, H. and M.. Carrier, 2013:A weak constraint 4D-Var assimilation system for the Navy Coastal Ocean Model using the representer method. Chapter 15 In "Data Assimilation for Atmospheric, Oceanic and Hydrological Applications, Vol II", Liang Xu and Seon Park, Eds. Springer, pp367-390.

Oke, P.R., G. Larnicol, E. M. Jones, V. Kourafalou, A. Sperrevik, F. Carse, C. A. S. Tanajura, B. Mourre, M. Tonani, G. B. Brassington, M. Le Henaff, G. R. Halliwell, R. Atlas, A. M. Moore, C. A. Edwards, M. J. Martin, A. A. Stellar, A. Alvarez, P. De Mey, and M. Iskandarani, 2015: Assessing the impact of observations on ocean forecasts and reanalyses: Part 2: Regional applications. J. Operational Oceanography, In press.

Pan C., M. Yaremchuk, D. Nechaev and H. Ngodock, 2011: Variational assimilation of glider data in Monterey Bay. J. Mar. Res., 69, 331-346.

Penven, P., I. Halo, S. Pous and L. Marie, 2014: Cyclogeostrophic balance in the Mozambique Channel. J. Geophys. Res., 119, 1054-1067.

Rio, M.H., P. Schaeffer and J.M. Lemoine, 2005: The estimation of the ocean mean synam- 
ics topography through the combination of altimetric data, in-situ measurements and GRACE geoid: From global to regional studies. Proc. GOCINA Int. workshop, Luxembourg. Centre Européen de Géodynamique et de Séismologie.

Saraceno, M., P.T. Strub and P.M. Kosro, 2008. Estimates of sea surface height and near surface alongshore coastal currents from combinations of altimeters and tide gauges. J. Geophys. Res., 113, C11013, doi:10.1029/2008JC004756.

Schroeder, I. D., J. A. Santora, A. M. Moore, C. A. Edwards, J. Fiechter, E. L. Hazen, S. J. Bograd, J. C. Field, and B. K. Wells (2014), Application of a data-assimilative regional ocean modeling system for assessing California Current System ocean conditions, drill, and juvenile rockfish interannual variability, Geophys. Res. Lett., 41, 5942-5950, doi:10.1002/2014GL061045.

Shchepetkin, A.F. and J.C. McWilliams, 2004: The regional oceanic modeling system (ROMS): a split explicit, free-surface, topography-following-coordinate oceanic model. Ocean Modeling, 9, 347-404.

Stegmann, P.M., and F. Schwing, 2007: Demographics of mesoscale eddies in the California Current. Geophys. Res. Letts., 34, L14602, doi:10.1029/2007GL029504.

Strub, P.T. and C. James, 2000: Altimeter-derived variability of surface velocities in the California Current System: 2. Seasonal circulation and eddy statistics. Deep Sea Res., Part II, 47, 831-870.

Sudre, J., C. Maes and V. Garçon, 2013: On the global estimates of geostrophic and Ekman surface currents. Limnology and Oceanography: Fluids and Environment, 3, 1-20.

Talagrand, O. and P. Courtier, 1987: Variational assimilation of meteorological observations with the adjoint vorticity equation. I: Theory. Q. J. R. Meteorol. Soc., 113, 1321-1328. 
Todd R.E.,D.L. Rudnick, M.R. Mazloff, R.E. Davis and B.D. Cornuelle, 2011: Poleward flows in the southern California Current System: glider observations and numerical simulation. J. Geophys. Res. 116, C02026.

Veneziani, M., C.A. Edwards, J.D. Doyle and D. Foley, 2009a: A central California coastal ocean modeling study: 1. Forward model and the influence of realistic versus climatological forcing. J. Geophys. Res., 114, C04015, doi:10.1029/2008JC004774.

Veneziani, M., C.A. Edwards and A.M. Moore, 2009b: A central California coastal ocean modeling study: 2. Adjoint sensitivities to local and remote forcing mechanisms. J. Geophys. Res., 114, C04020, doi:10.1029/2008JC004775.

Weaver, A.T. and P. Courtier, 2001: Correlation modelling on the sphere using a generalized diffusion equation. Q. J. R. Meteorol. Soc., 127, 1815-1846.

Weaver, A.T., C. Deltel, E. Machu, S. Ricci and N. Daget, 2005: A multivariate balance operator for variational ocean data assimilation. Q. J. R. Meteorol. Soc., 131, 36053625.

Weaver, A.T., J. Vialard and D.L.T. Anderson, 2003: Three- and four-dimensional variational assimilation with a general circulation model of the tropical Pacific Ocean. Part I: Formulation, internal diagnostics and consistency checks. Mon. Wea. Rev., 131, 1360-1378.

Weiss, J., 1991: The dynamics of enstrophy transfer in two-dimensional hydrodynamics. Physica D, 48, 273-294.

Wikle, C.K. and L.M. Berliner, 2007: A Bayesian tutorial for data assimilation. Physica D, $230,1-16$.

Willis, J.K., D. Roemmich and B.D. Cornuelle, 2004: Interannual variability in upper ocean 
1153

1154

1155

1156

1157

1158

1159

heat content, temperature, and thermosteric expansion on global scales. J. of Geophys. Res., 109, C12036, doi:10.1029/2003JC002260.

Wunsch, C. and P. Heimbach, 2007: Practical global ocean state estimation. Physica D, 230, 197-208.

Yu P., A.L. Kurapov, G.D. Egbert, J.S. Allen and P.M. Kosro, 2012: Variational assimilation of HnF radar surface currents in a coastal ocean model off Oregon. Ocean Modelling, 49, 86-104. 
1160 $1170 \quad(\zeta)$

1171 1172 1173 (surface heat flux in $\mathrm{W} \mathrm{m}^{-2}$ ) between the data sets indicated. The numbers highlighted ${ }_{1174}$ in red correspond to the rms differences between the 4D-Var posterior and prior estimates. 1175 $1176=$ WCRA31 posterior estimates; WCRA14 = WCRA14 posterior estimates; NARR $=$ North 1177 American Regional Reanalysis from NCEP; CaRD10 = California Reanalysis Downscaling 1178 1179

Table 1: A summary of the observation types, observing platforms, data sources, the nominal measurement errors, and the period covered.

Table 2: A summary of the correlation length scales used for the background errors for the different components of B. For the surface forcing, $\left(\tau_{x}, \tau_{y}\right)$ denotes the zonal and meridional components of the surface wind stress, $Q_{H}$ is the surface heat flux, and $Q_{W}$ is the net surface freshwater flux. In the case of the background errors in the open boundary conditions and initial conditions, the first number represents the horizontal correlation length while the second number is the vertical correlation length. The state variables listed are the two horizontal components of velocity $(u, v)$, temperature $(T)$, salinity $(S)$ and sea surface height

Table 3: Mean and standard deviation of the posterior minus prior fields for WCRA31.

Table 4: The root mean square (rms) difference between surface wind stress in $\mathrm{N} \mathrm{m}^{-2}$ $\mathrm{CCMP} / \mathrm{ERA}=$ the combination of CCMP and ERA products used in WCRA31; WCRA31 to $10 \mathrm{~km}$ from Scripps Institute of Oceanography; Qscat = QuikSCAT wind product from NOAA Coastwatch. 


\section{Figure Captions}

Figure 1: The ROMS domain and bathymetry (depth in m) used in WCRA31 and WCRA14. Also shown are the regions considered in section 5.1 and the CalCOFI lines considered in section 5.5 (white dashed lines).

Figure 2: A time series of $\log _{10}$ of the total number of super observations available from EN3 and each satellite observing platform within the ROMS CCS model domain during each month of the year during the period spanned by WCRA31. Dark blue: In situ observations from EN3; Red: SST from AVHRR/PathFinder; Black: SST from AMSR-E; Green: MODISTerra; Magenta: SSH from AVISO; Light blue: observations rejected.

Figure 3: A schematic illustrating the overlapping 8 day data assimilation cycles used in WCRA14 and WCRA31. The starting time for cycle $j$ is denoted as $t_{0}^{j}$ and the mid-point as $t_{0}^{j}+4$. As indicated, the ending time of 4D-Var analysis cycle $j$ corresponds to the mid-point of cycle $j+1$ and the starting time of cycle $j+2$. The prior circulation initial condition for cycle $j+1$ is taken as the posterior circulation estimate at the mid-point of cycle $j$.

Figure 4: Time series of the initial (blue curve) and final (red curve) cost function (7) for each 4D-Var cycle for (a) WCRA31 and (b) WCRA31. Also shown are the values of the nonlinear cost function (2) (green crosses).

Figure 5: Probability density functions of the innovations for observations of (a) SSH, (b) temperature, and (c) salinity. The red line in each case shows the probability density function of a normal distribution with the same mean and standard deviation.

Figure 6: (a) A scatter plot of $\operatorname{Tr}\{\mathbf{T}\}$ vs randomized estimates of $\operatorname{Tr}\left\{\mathbf{R}^{-1} \mathbf{G D G} \mathbf{G}^{T}\right\}$ for a selection of 4D-Var cycles during 1991 and 2000. The best least-squares straight line fit is 
indicated by the dashed line. (b) Time series from WCRA31 of $s$ (red line) and $\mathbf{d}^{T} \mathbf{R}^{-1} \mathbf{d}$ (black line). (c) A scatter plot of $\operatorname{Tr}\left\{\mathbf{R}^{-1} \mathbf{F} \mathbf{D F}^{T}\right\}$ vs $\operatorname{Tr}\left\{\mathbf{R}^{-1} \mathbf{G} \mathbf{D G} \mathbf{G}^{T}\right\}$. The 1-to-1 line is also shown. Time series from WCRA31 of $\operatorname{Tr}\left\{\mathbf{F D F}{ }^{T}\right\}$ (red line) and $\mathbf{d}^{T} \mathbf{d}_{b}^{a}$ (black line) for observations of (d) temperature, (e) salinity and (f) SSH. Time series from WCRA31 of $\operatorname{Tr}\{\mathbf{R}\}$ (red line) and $\mathbf{d}^{T} \mathbf{d}_{a}^{o}$ (black line) for observations of (g) temperature, (h) salinity and (i) SSH.

Figure 7: The mean increments for (a) SST and (b) SSS computed from all 4D-Var analysis cycles of WCRA31. The standard deviations of the increments are shown in (c) for SST and (d) for SSS.

Figure 8: Time series of the posterior minus prior fields of WCRA31 averaged over the different regions in Fig. 8 for: (a) R1 SST, (b) R2 SSH, (c) R2 SSS and (d) R1 EKE.

Figure 9: Time series of the WCRA31 posterior (red) and forward (blue) fields averaged over the different regions in Fig. 8 for: (a) R2 SST, (b) R1 SSH, (c) R4 SSS and (d) R1 EKE.

Figure 10: The mean posterior zonal and meridional surface wind stress averaged over all assimilation cycles for (a,b) WCRA31, and (c,d) WCRA14. Also shown are the differences between the posterior and prior zonal and meridional surface wind stress components for $(\mathrm{e}, \mathrm{f})$ WCRA31, and $(\mathrm{g}, \mathrm{h})$ WCRA14.

Figure 11: The mean posterior total surface heat flux averaged over all assimilation cycles for (a) WCRA31, and (c) WCRA14. Also shown are the differences between the posterior and prior surface heat flux averaged over all assimilation cycles for (b) WCRA31, and (d) WCRA14.

Figure 12: The mean posterior total surface freshwater flux (mm day-1) averaged over all 
assimilation cycles for (a) WCRA31, and (c) WCRA14. A positive flux is out of the ocean (i.e. excess evaporation over precipitation). Also shown are the differences between the posterior and prior surface freshwater flux for (b) WCRA31, and (d) WCRA14.

Figure 13: The time mean surface EKE difference between WCRA31 and the forward model run without data assimilation (TJoules). The region indicated by the black box is referred to in section 5.4 .

Figure 14: The difference in depth avereaged EKE over the upper $500 \mathrm{~m}$ between WCRA31 and the forward model run without data assimilation and averaged between Point Conception $\left(34^{\circ} \mathrm{N}\right)$ and Cape Blanco $\left(43^{\circ} \mathrm{N}\right)$ as a function of offshore distance from the coast (TJoules).

Figure 15: (a) Time series of the three month running mean of the total number of eddies in WCRA31 (red) and the forward model without data assimilation (blue). (b) Times series of the ratio of the three month running mean of the number of ageostrophic eddies to geostrophic eddies in WCRA31 (red) and the forward run (blue). The number of eddies from a run of the model where data assimilation ceases on 17 Feb. 1995 is also shown (green). (c) Probability density functions (PDFs) of eddy diameter in WCRA31 (red) and the forward model (blue). (d) The PDF for geostrophic eddies (red) and ageostrophic eddies (blue) in WCRA31.

Figure 16: Vertical profiles of the comparison between the model and the CalCOFI observations for (a) WCRA31 and (b) the forward model run for the period Mar. 1990 - Jul. 2007. The statistics for temperature (salinity) are shown in the left (right) of each panel. The black line is the mean of the differences between the model (M) and the observational 
1246 data (D). The standard deviation of the difference M-D is shown in blue. The standard 1247 deviations of the model and the data are shown in red and green, respectively. 


\begin{tabular}{|c|c|c|c|c|}
\hline $\begin{array}{c}\text { Observation } \\
\text { Type }\end{array}$ & $\begin{array}{l}\text { Observing } \\
\text { Platform }\end{array}$ & Source & $\begin{array}{c}\text { Instrument } \\
\text { Error }\end{array}$ & $\begin{array}{c}\text { Period } \\
\text { Covered }\end{array}$ \\
\hline SSH & Altimeter & $\begin{array}{l}\text { Aviso, } 1 \text { day } \\
\text { average }\end{array}$ & $0.04 \mathrm{~m}$ & $\begin{array}{c}1993- \\
2012\end{array}$ \\
\hline SST & $\begin{array}{l}\text { AVHRR/ } \\
\text { Pathfinder }\end{array}$ & $\begin{array}{c}\text { NOAA Coast } \\
\text { Watch }\end{array}$ & $0.6^{\circ} \mathrm{C}$ & $\begin{array}{l}1981- \\
2012\end{array}$ \\
\hline SST & AMSR-E & $\begin{array}{c}\text { NOAA Coast } \\
\text { Watch }\end{array}$ & $0.7^{\circ} \mathrm{C}$ & $\begin{array}{l}2002- \\
2010\end{array}$ \\
\hline SST & $\begin{array}{l}\text { MODIS- } \\
\text { Terra }\end{array}$ & NASA JPL & $0.3^{\circ} \mathrm{C}$ & $\begin{array}{l}2000- \\
2012\end{array}$ \\
\hline $\begin{array}{c}\text { Hydrographic } \\
\text { data }\end{array}$ & Various & $\begin{array}{c}\text { UK } \\
\text { Meteorological } \\
\text { Office }\end{array}$ & $\begin{array}{c}0.5^{\circ} \mathrm{C} \text { for } \mathrm{T} \\
0.1 \text { for } \mathrm{S}\end{array}$ & $\begin{array}{c}1950- \\
2012\end{array}$ \\
\hline
\end{tabular}

Table 1: A summary of the observation types, observing platforms, data sources, the nominal measurement errors, and the period covered. 


\begin{tabular}{llllll}
\hline Prior & & & & & \\
\hline Forcing & $\tau_{\mathrm{x}} 300 \mathrm{~km}$ & $\tau_{\mathrm{y}} 300 \mathrm{~km}$ & $\mathrm{Q}_{\mathrm{H}} 100 \mathrm{~km}$ & $\mathrm{Q}_{\mathrm{W}} 100 \mathrm{~km}$ & \\
\hline $\begin{array}{l}\text { Open } \\
\text { boundaries }\end{array}$ & $\mathrm{u} 100 \mathrm{~km}, 30 \mathrm{~m}$ & $\mathrm{v} 100 \mathrm{~km}, 30 \mathrm{~m}$ & $\begin{array}{l}\mathrm{T} 100 \mathrm{~km}, 30 \\
\mathrm{~m}\end{array}$ & $\mathrm{~S} 100 \mathrm{~km}, 30 \mathrm{~m}$ & $\zeta 100 \mathrm{~km}$ \\
\hline $\begin{array}{l}\text { Initial } \\
\text { conditions }\end{array}$ & $\mathrm{u} 50 \mathrm{~km}, 30 \mathrm{~m}$ & $\mathrm{v} 50 \mathrm{~km}, 30 \mathrm{~m}$ & $\mathrm{~T} 50 \mathrm{~km}, 30 \mathrm{~m}$ & $\mathrm{~S} 50 \mathrm{~km}, 30 \mathrm{~m}$ & $\zeta 50 \mathrm{~km}$ \\
\hline
\end{tabular}

Table 2: A summary of the correlation length scales used for the background errors for the different components of $\mathbf{D}$. For the surface forcing, $\left(\tau_{x}, \tau_{y}\right)$ denotes the zonal and meridional components of the surface wind stress, $\mathrm{Q}_{\mathrm{H}}$ is the surface heat flux, and $\mathrm{Q}_{\mathrm{W}}$ is the net surface freshwater flux. In the case of the background errors in the open boundary conditions and initial conditions, the first number represents the horizontal correlation length while the second number is the vertical correlation length. The state variables listed are the two horizontal components of velocity (u,v), temperature (T), salinity (S) and sea surface height $(\zeta)$. 


\begin{tabular}{lcccc}
\hline Variable & R1 (mean, std) & R2 (mean, std) & R3 (mean, std) & R4 (mean, std) \\
\hline$\Delta$ SST $\left({ }^{\circ} \mathrm{C}\right)$ & $-6 \times 10^{-2}, 0.24$ & $-7 \times 10^{-2}, 0.24$ & $-6 \times 10^{-3}, 0.25$ & $-8 \times 10^{-2}, 0.21$ \\
\hline$\Delta$ SSH $(\mathrm{m})$ & $-2 \times 10^{-3}, 1.6 \times 10^{-2}$ & $-2 \times 10^{-3}, 1.6 \times 10^{-2}$ & $-1 \times 10^{-3}, 1.5 \times 10^{-2}$ & $-1 \times 10^{-3}, 1.6 \times 10^{-2}$ \\
\hline$\Delta$ SSS & $-3 \times 10^{-3}, 1.1 \times 10^{-2}$ & $-4 \times 10^{-3}, 1.2 \times 10^{-2}$ & $-4 \times 10^{-3}, 9 \times 10^{-3}$ & $-2 \times 10^{-3}, 4 \times 10^{-3}$ \\
\hline$\Delta$ KE (TJoules) & $9.2,23$ & $1.5,22$ & $3.4,17$ & $-37,110$ \\
\hline
\end{tabular}

Table 3: Mean and standard deviation of the posterior minus prior fields for WCRA31. 


\begin{tabular}{lcccccc}
\hline Model & WCRA31 & COAMPS & WCRA14 & NARR & CaRD10 & Qscat \\
\hline CCMP/ERA & $\mathbf{0 . 0 3 8 ~ ( 4 0 )}$ & 0.091 & & 0.117 & 0.273 & 0.061 \\
& & $(147)$ & & $(148)$ & $(121)$ & \\
\hline WCRA31 & & & 0.098 & & & 0.070 \\
& & & $(151)$ & & & \\
\hline COAMPS & & $\mathbf{0 . 0 3 7}(73)$ & 0.057 & 0.262 & 0.059 \\
& & & & $(67)$ & $(78)$ & \\
\hline WCRA14 & & & & 0.239 & 0.059 \\
\hline NARR & & & & & & 0.248 \\
\hline CaRD10 & & & & & & \\
\hline
\end{tabular}

Table 4: The root mean square (rms) difference between surface wind stress in $\mathrm{Nm}^{-2}$ (surface heat flux in $\mathrm{Wm}^{-2}$ ) between the data sets indicated. The numbers highlighted in red correspond to the rms differences between the 4D-Var posterior and prior estimates. CCMP/ERA = the combination of CCMP and ERA products used in WCRA31; WCRA31 = WCRA31 posterior estimates; WCRA14 = WCRA14 posterior estimates; NARR = North American Regional Reanalysis from NCEP; CaRD10 = California Reanalysis Downscaling to 10km from Scripps Institute of Oceanography; Qscat = QuikSCAT wind product from NOAA Coastwatch. 


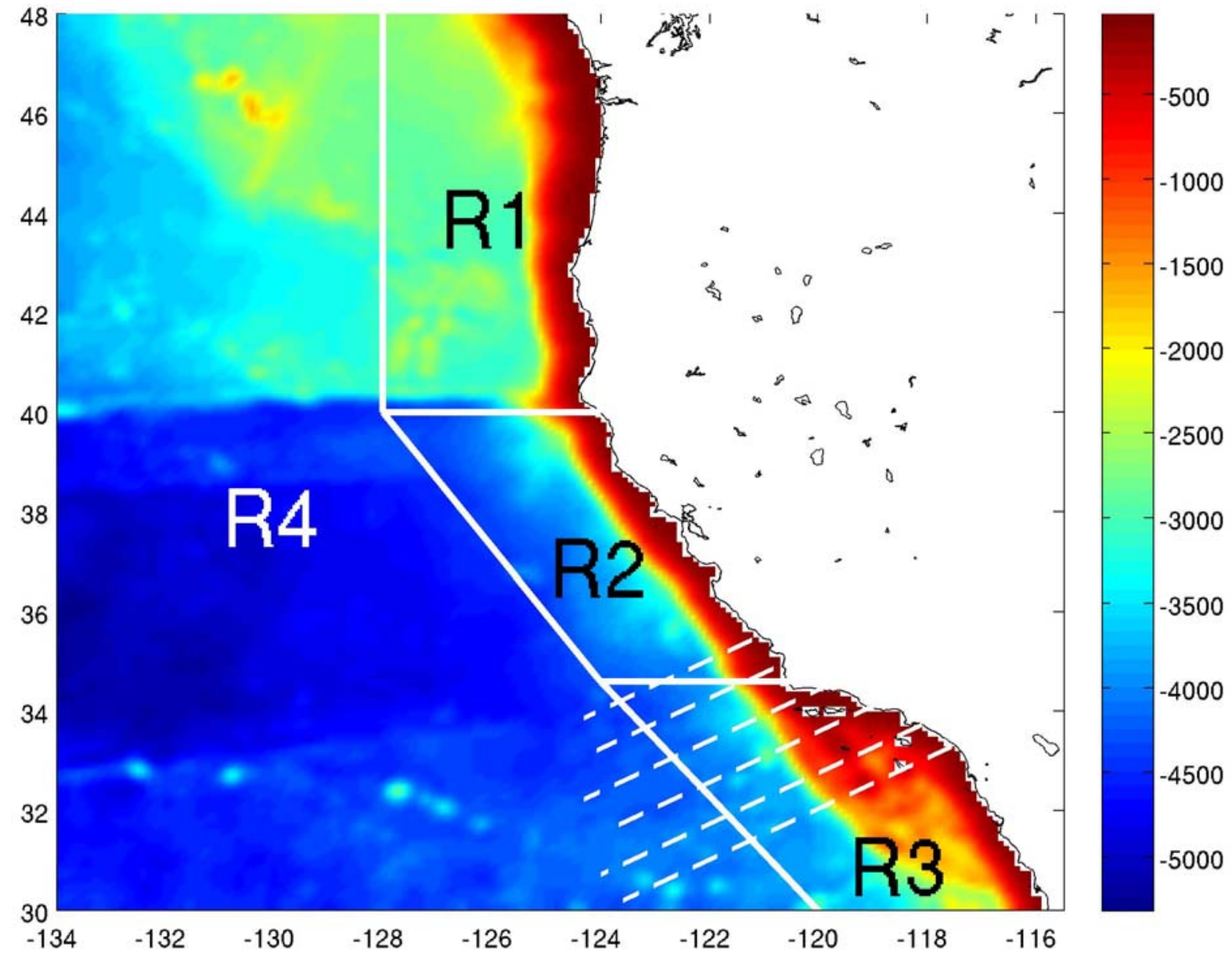

Figure 1: The ROMS domain and bathymetry (depth in m) used in WCRA31 and WCRA14. Also shown are the regions considered in section 5.1 and the CalCOFI lines considered in section 5.5 (white dashed lines). 


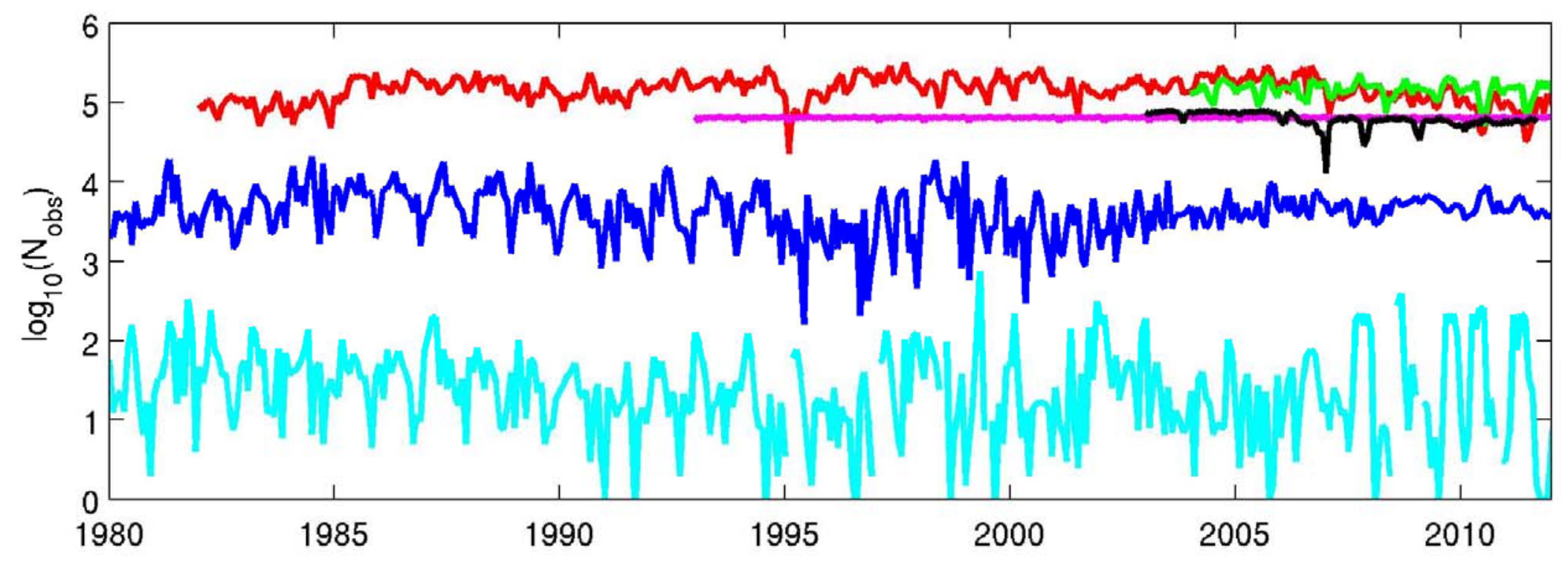

Figure 2: A time series of $\log _{10}$ of the total number of super observations available from EN3 and each satellite observing platform within the ROMS CCS model domain during each month of the year for the period spanned by WCRA31. Dark blue: In situ observations from EN3; Red: SST from AVHRR/PathFinder; Black: SST from AMSR-E; Green: SST from MODIS-Terra; Magenta: SSH from Aviso; Light blue: observations rejected. 


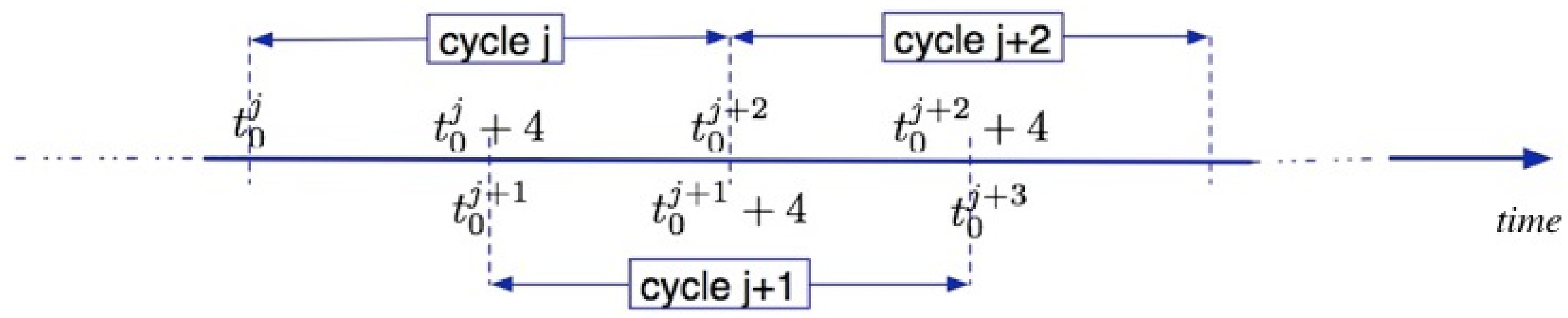

Figure 3: A schematic illustrating the overlapping 8 day data assimilation cycles used in WCRA14 and WCRA31. The starting time for cycle $j$ is denoted as $t_{0}{ }^{j}$ and the mid-point as $t_{0}{ }^{j}+4$. As indicated, the ending time of 4D-Var analysis cycle $j$ corresponds to the mid-point of cycle $j+1$ and the starting time of cycle $j+2$. The prior circulation initial condition for cycle $j+1$ is taken as the posterior circulation estimate at the mid-point of cycle $j$. 

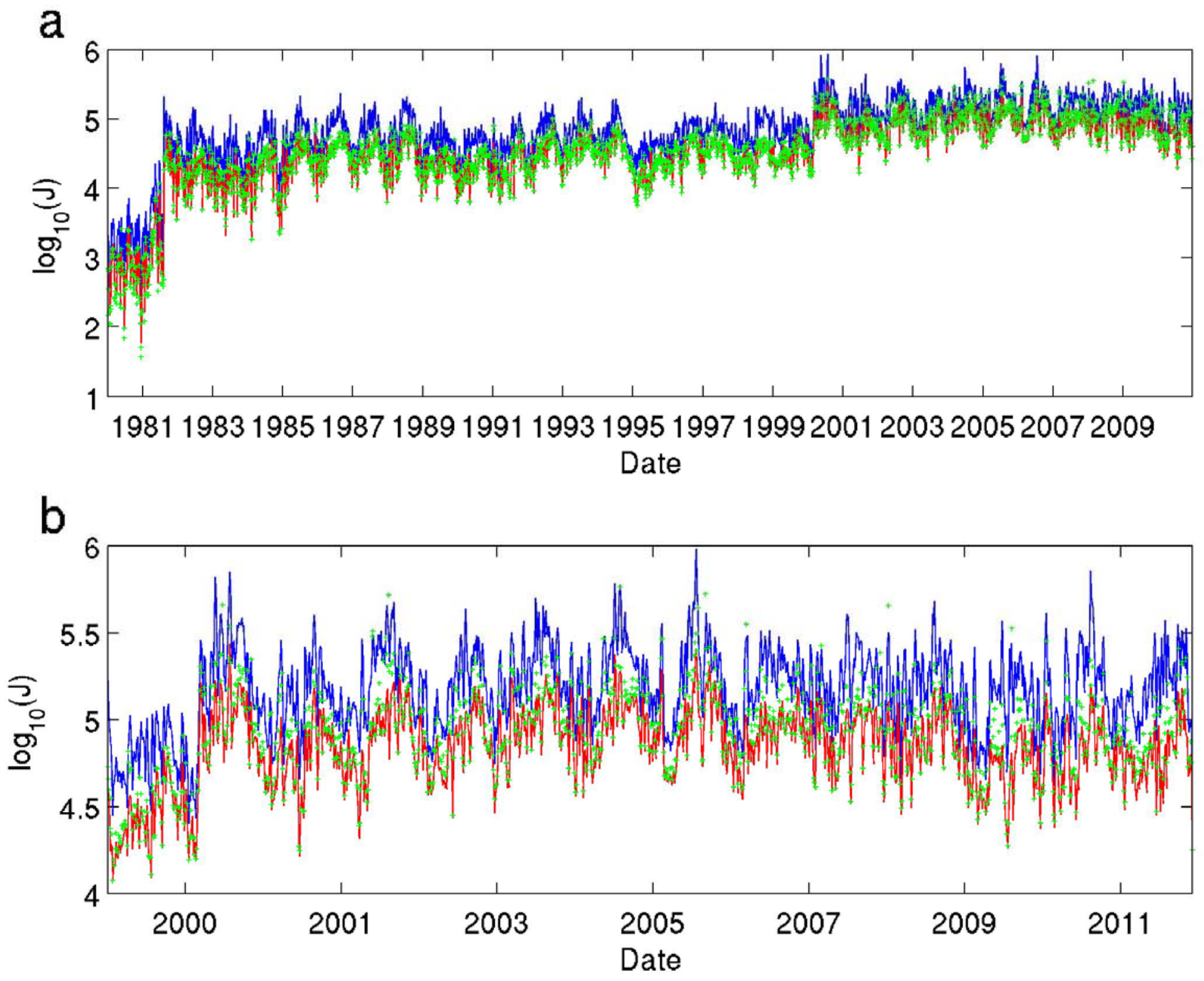

Figure 4: Time series of the initial (blue curve) and final (red curve) cost function (7) for each 4D-Var cycle for (a) WCRA31 and (b) WCRA14. Also shown are the values of the nonlinear cost function (2) (green crosses). 

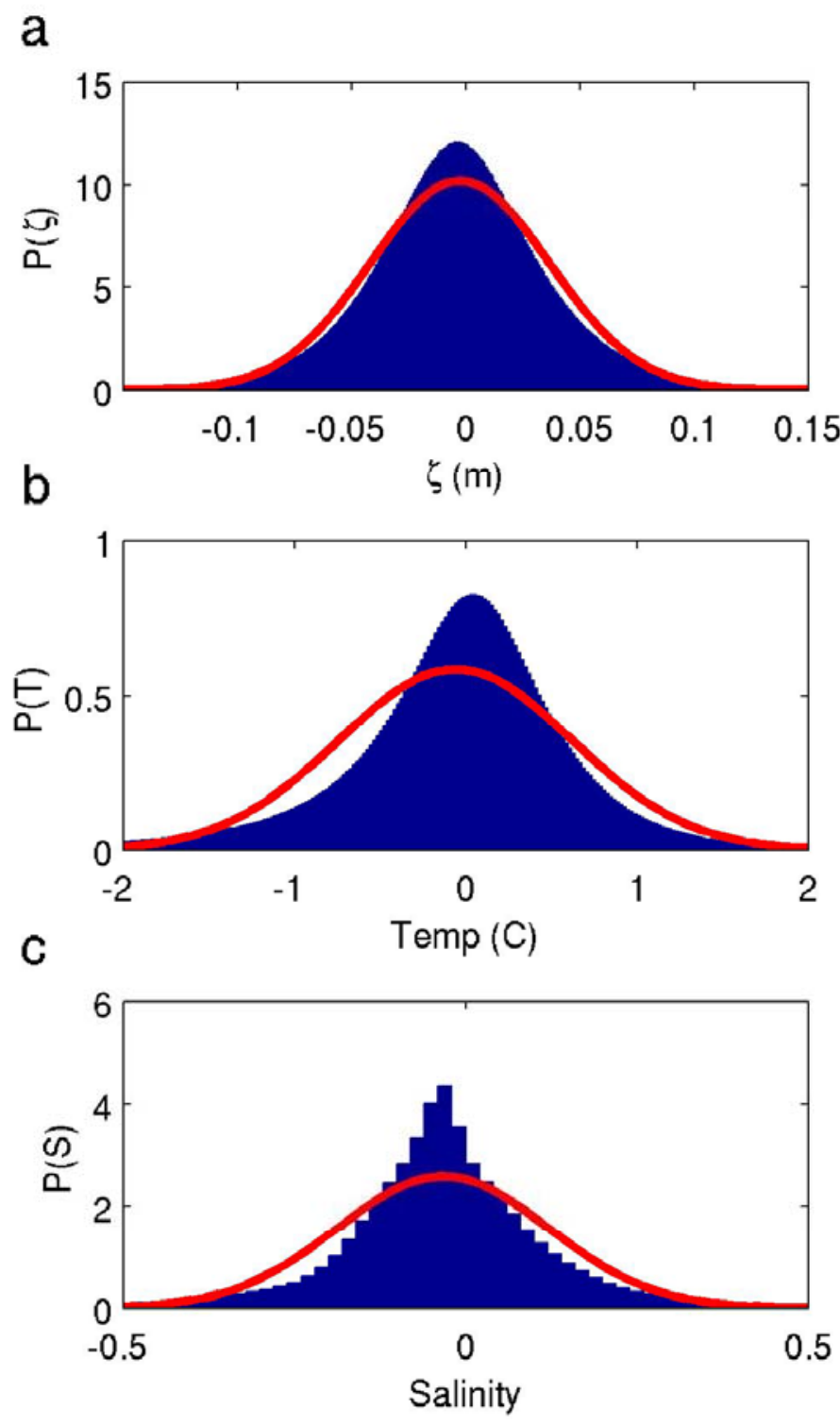

Figure 5: Probability density functions of the WCRA31 innovations for observations of (a) SSH, (b) temperature, and (c) salinity. The red line in each case shows the probability density function of a normal distribution with the same mean and standard deviation. 

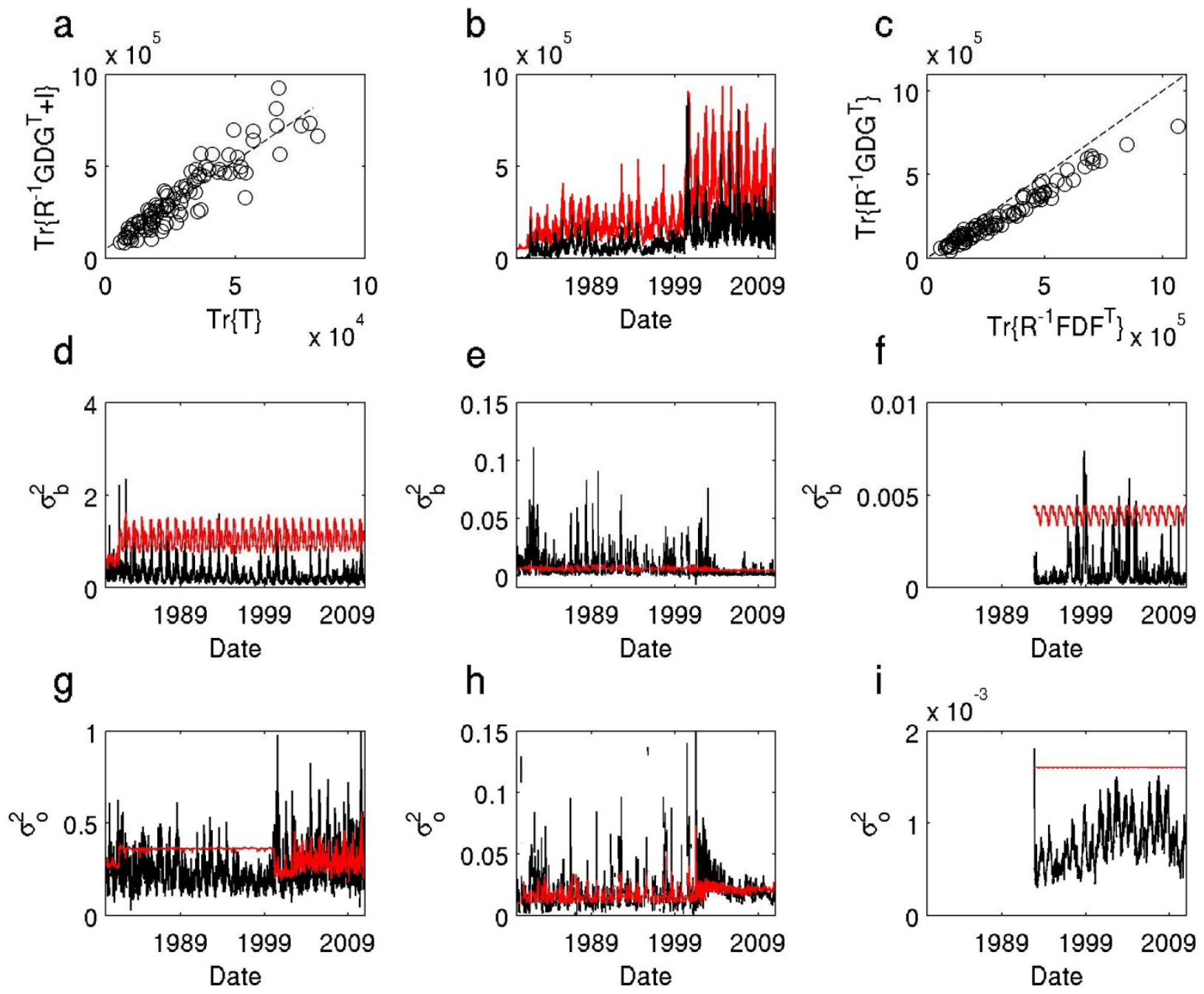

Figure 6: (a) A scatter plot of $\operatorname{Tr}\{\mathbf{T}\}$ vs randomized estimates of $\operatorname{Tr}\left\{\mathbf{R}^{-1} \mathbf{G D G}^{\mathrm{T}}\right\}$ for a selection of 4D-Var cycles during 1991 and 2000. The best least-squares straight line fit is indicated by the dashed line. (b) Time series from WCRA31 of $s$ (red line) and $\mathbf{d}^{\mathrm{T}} \mathbf{R}^{-1} \mathbf{d}$ (black line). (c) A scatter plot of $\operatorname{Tr}\left\{\mathbf{R}^{-1} \mathbf{F D F} \mathbf{F}^{\mathrm{T}}\right\}$ vs $\operatorname{Tr}\left\{\mathbf{R}^{-1} \mathbf{G D G}^{\mathrm{T}}\right\}$. The 1-to-1 line is also shown. Time series from WCRA31 of $\operatorname{Tr}\left\{\mathbf{F D F}^{\mathrm{T}}\right\}$ (red line) and $\mathbf{d}^{\mathrm{T}} \mathbf{d}_{\mathrm{b}}^{\mathrm{a}}$ (black line) for observations of $(\mathrm{d})$ temperature, (e) salinity and (f) SSH. Time series from WCRA31 of $\operatorname{Tr}\{\mathbf{R}\}$ (red line) and $\mathbf{d}^{\mathrm{T}} \mathbf{d}_{\mathrm{a}}^{\mathrm{O}}$ (black line) for observations of (g) temperature, (h) salinity and (i) SSH. 

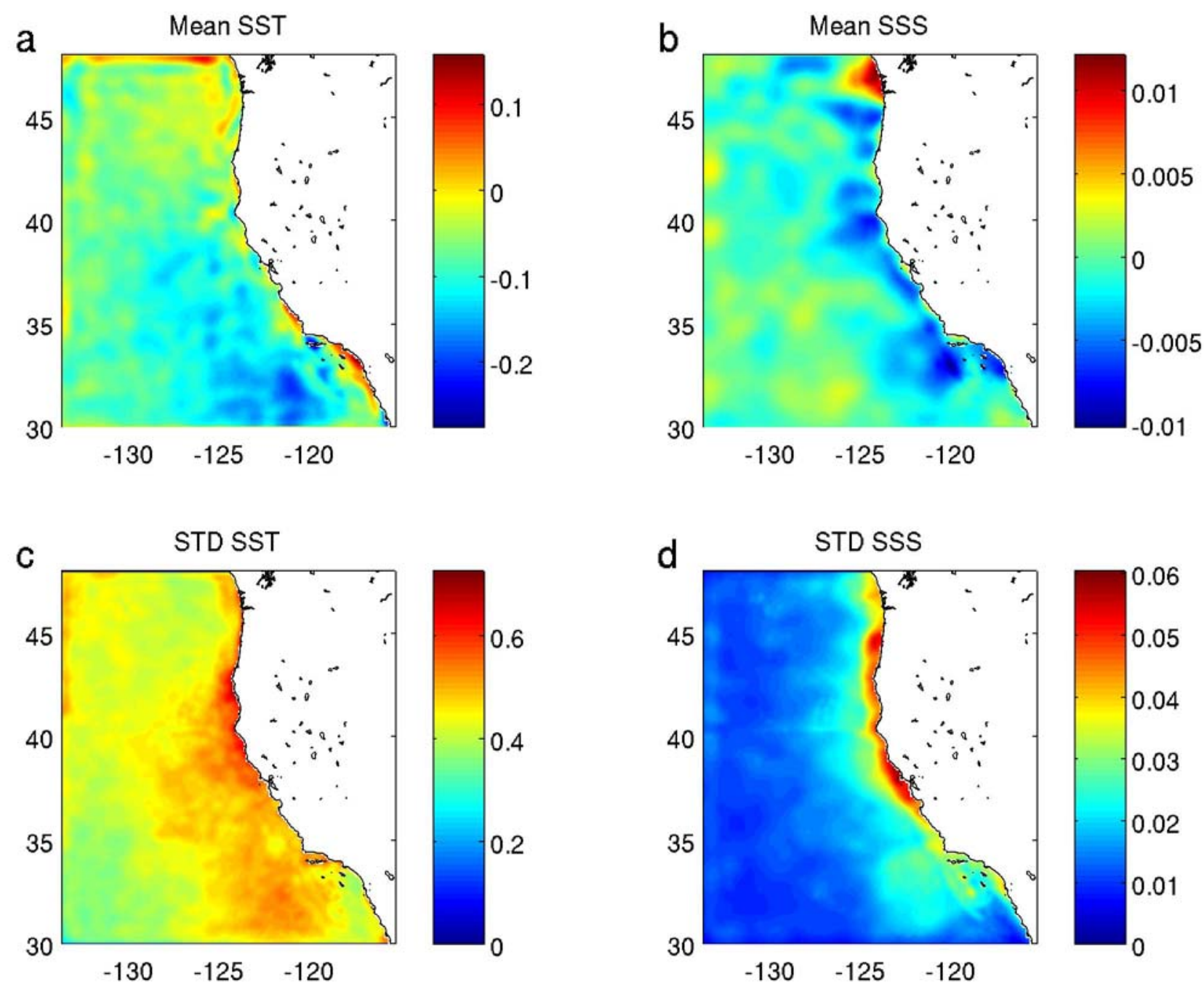

Figure 7: The mean increments for (a) SST and (b) SSS computed from all 4D-Var analysis cycles of WCRA31. The standard deviations of the increments are shown in (c) for SST and (d) for SSS. 
a

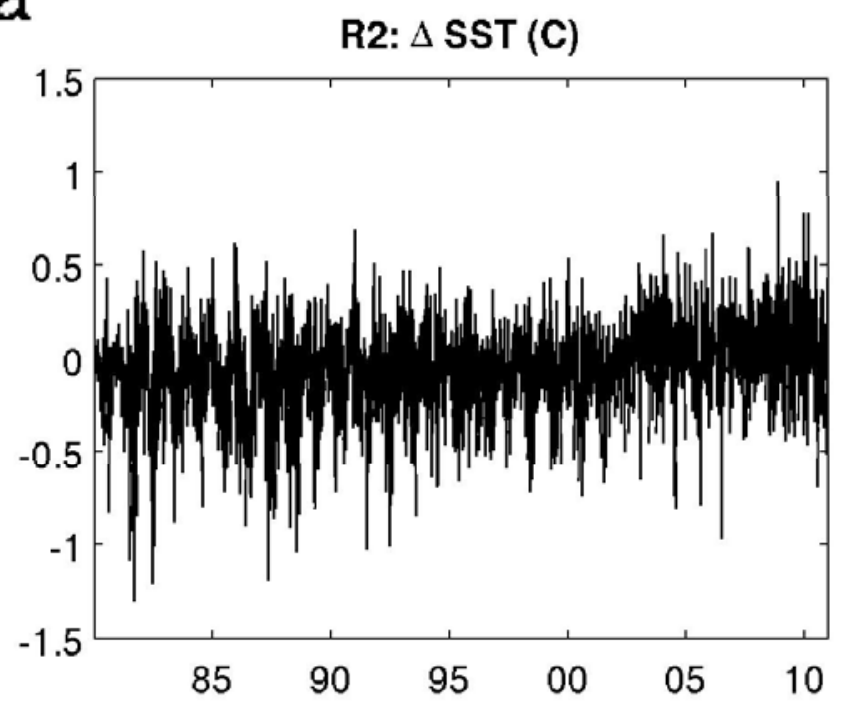

C

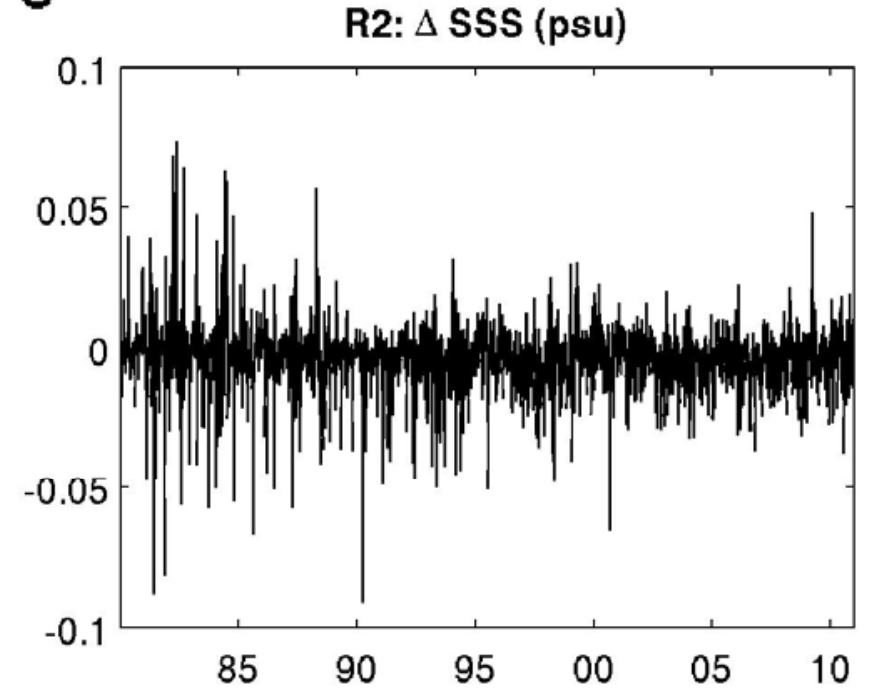

b

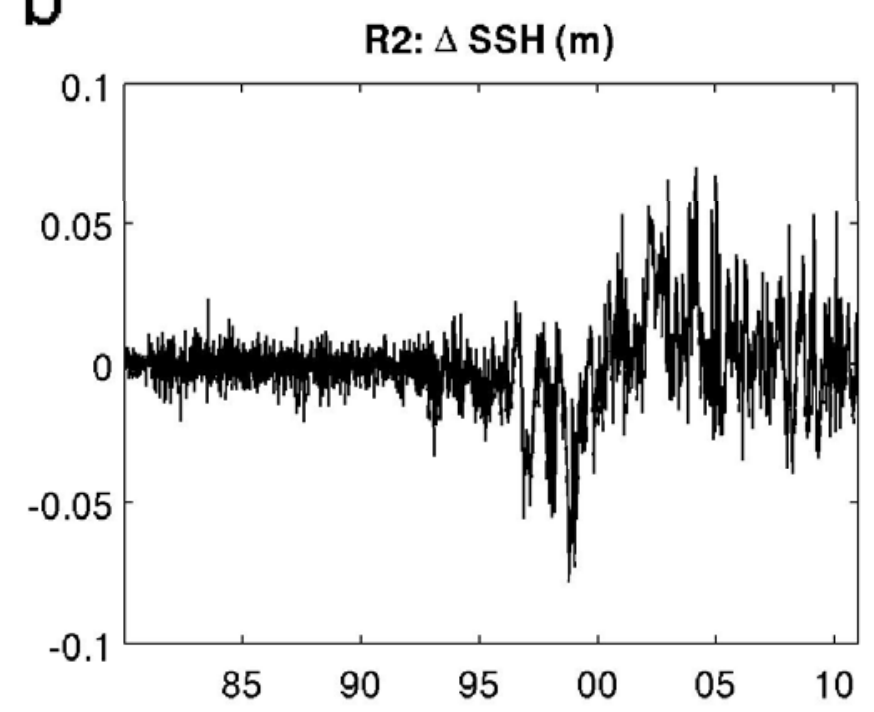

d

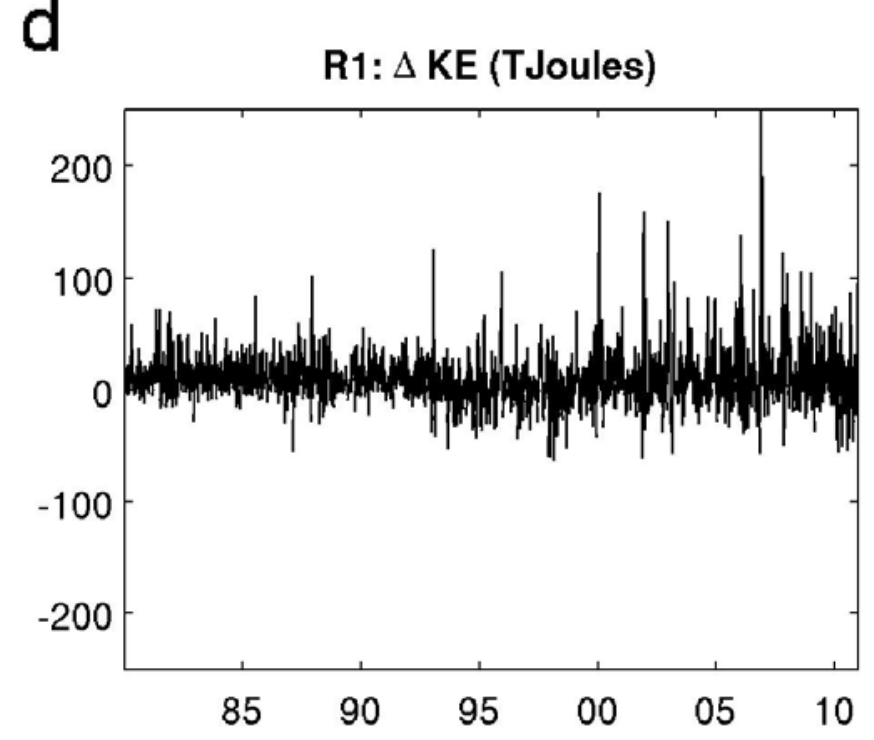

Figure 8: Time series of the posterior minus prior fields of WCRA31 averaged over the different regions in Fig. 8 for: (a) R2 SST, (b) R2 SSH, (c) R2 SSS and (d) R1 EKE. 
a

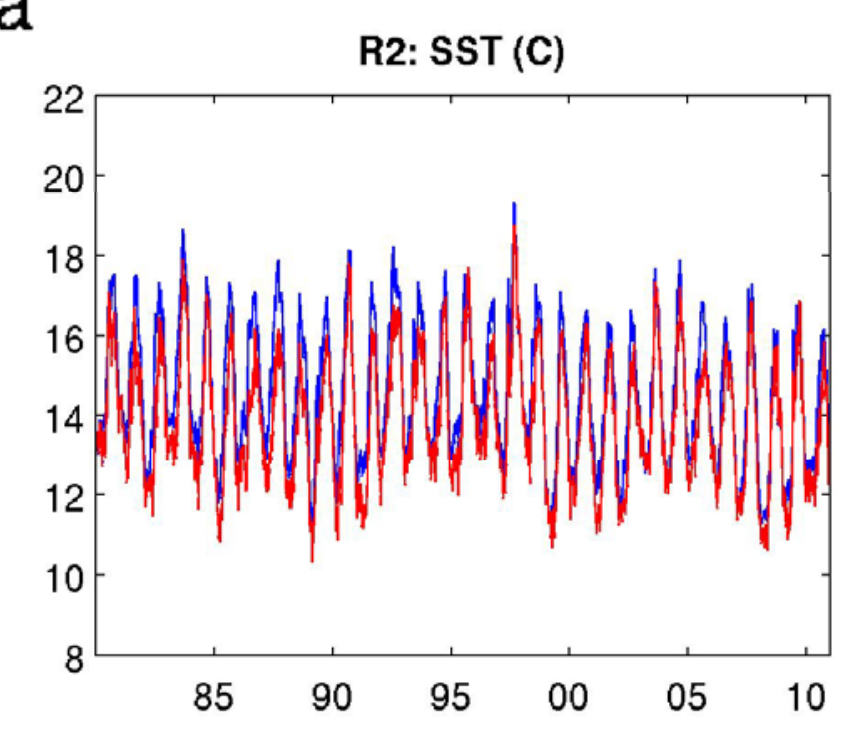

C

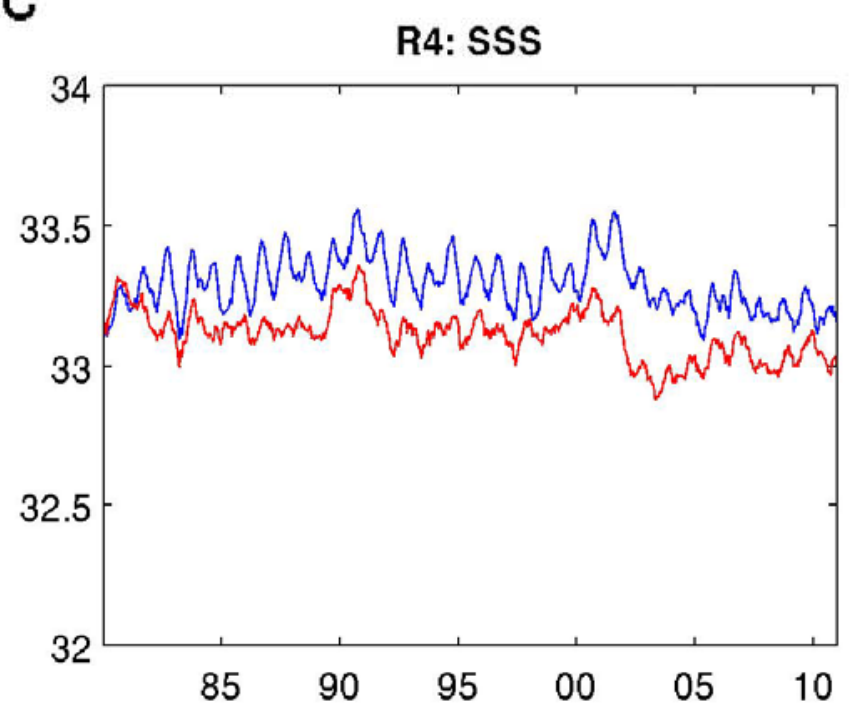

b
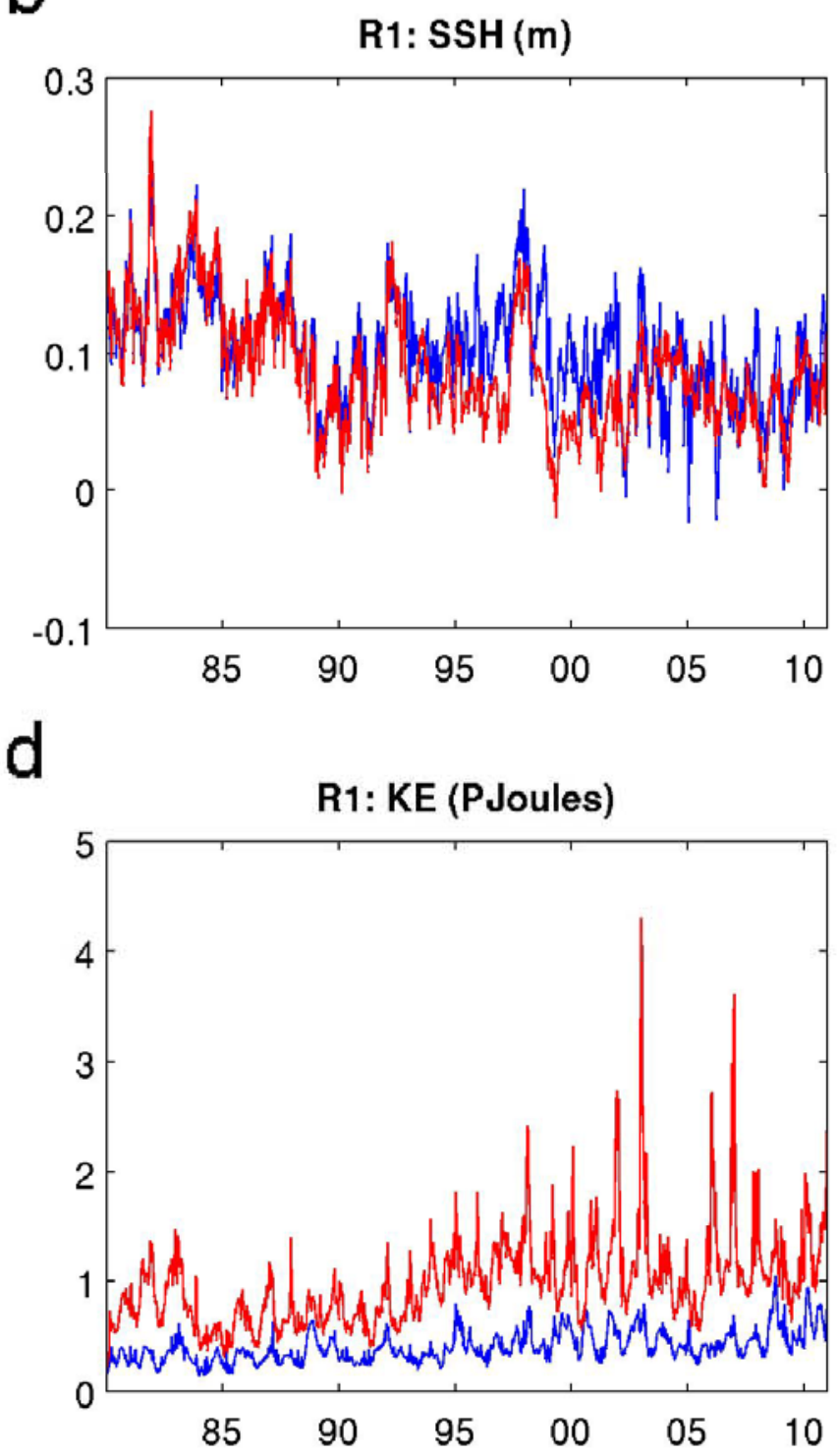

Figure 9: Time series of the WCRA31 posterior (red) and forward (blue) fields averaged over the different regions in Fig. 8 for: (a) R2 SST, (b) R1 SSH, (c) R4 SSS and (d) R1 EKE. 

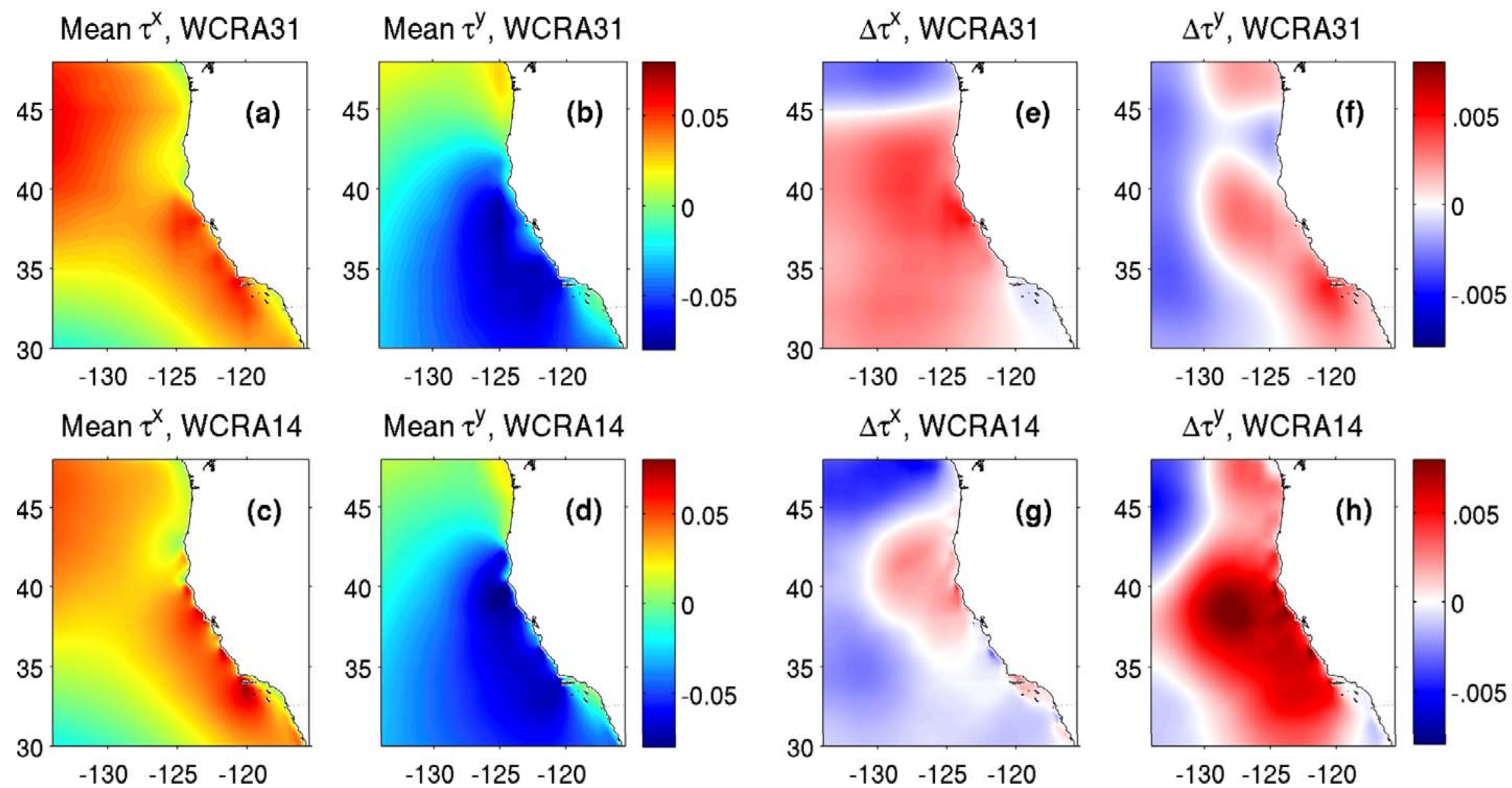

Figure 10: The mean posterior zonal and meridional surface wind stress averaged over all assimilation cycles for (a,b) WCRA31, and (c,d) WCRA14.Also shown are the differences between the posterior and prior zonal and meridional surface wind stress components for (e,f) WCRA31, and (g,h) WCRA14. 


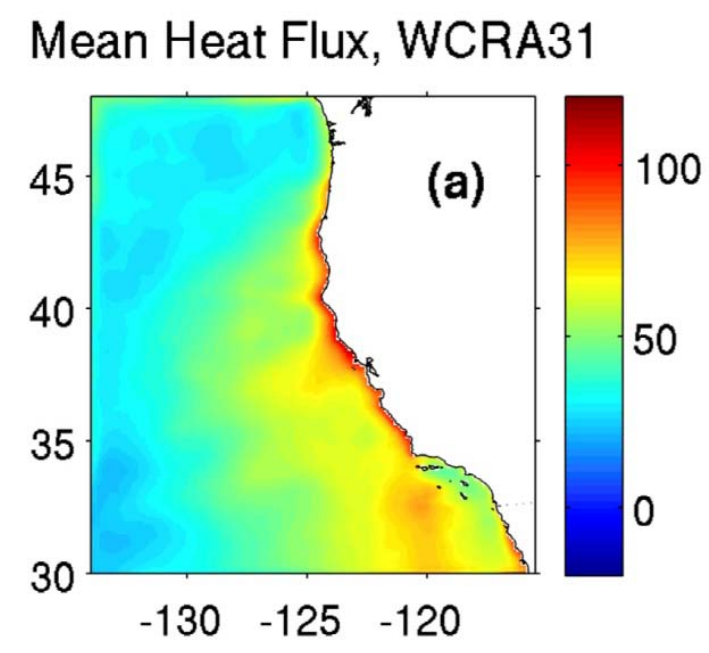

$\Delta$ Heat Flux, WCRA31

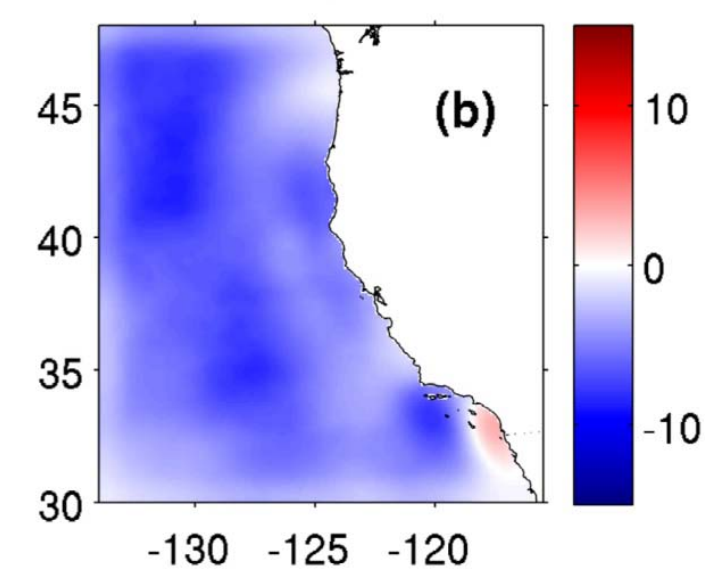

Mean Heat Flux, WCRA14

$\Delta$ Heat Flux, WCRA14
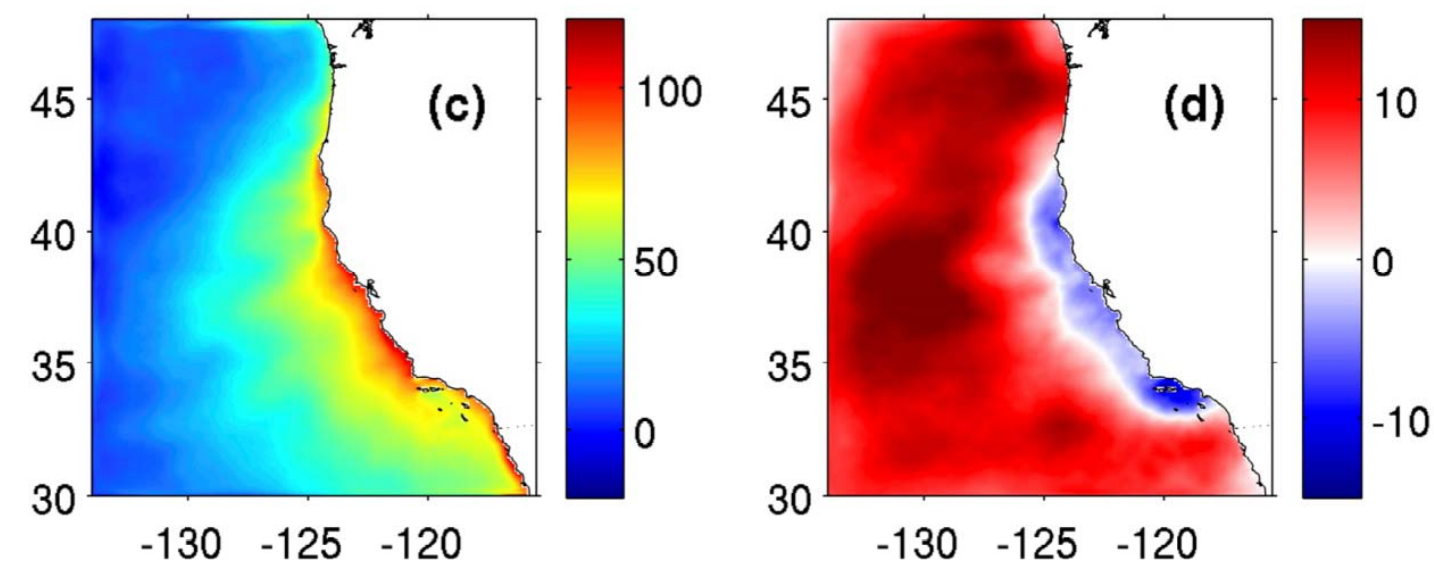

Figure 11: The mean posterior total surface heat flux averaged over all assimilation cycles for (a) WCRA31, and (c) WCRA14. Also shown are the differences between the posterior and prior surface heat flux averaged over all assimilation cycles for (b) WCRA31, and (d) WCRA14. 


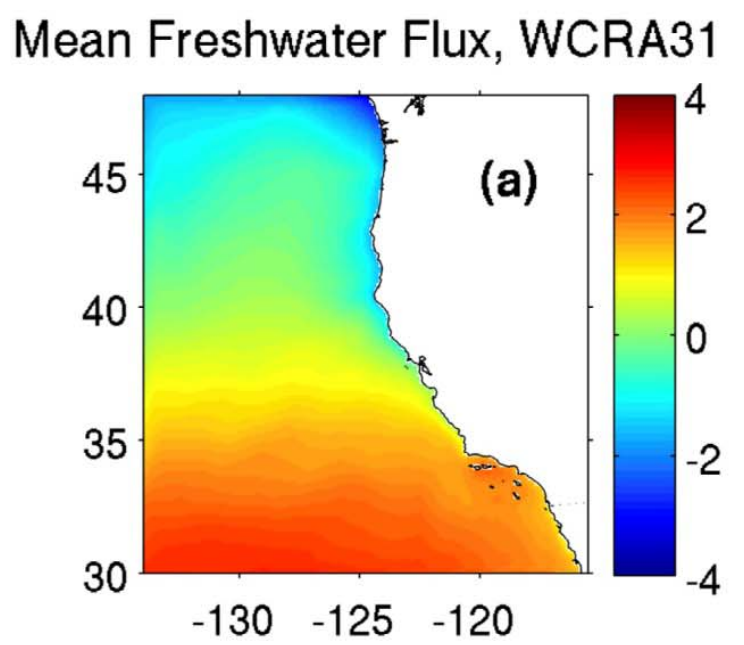

$\Delta$ Freshwater Flux, WCRA31

Mean Freshwater Flux, WCRA14
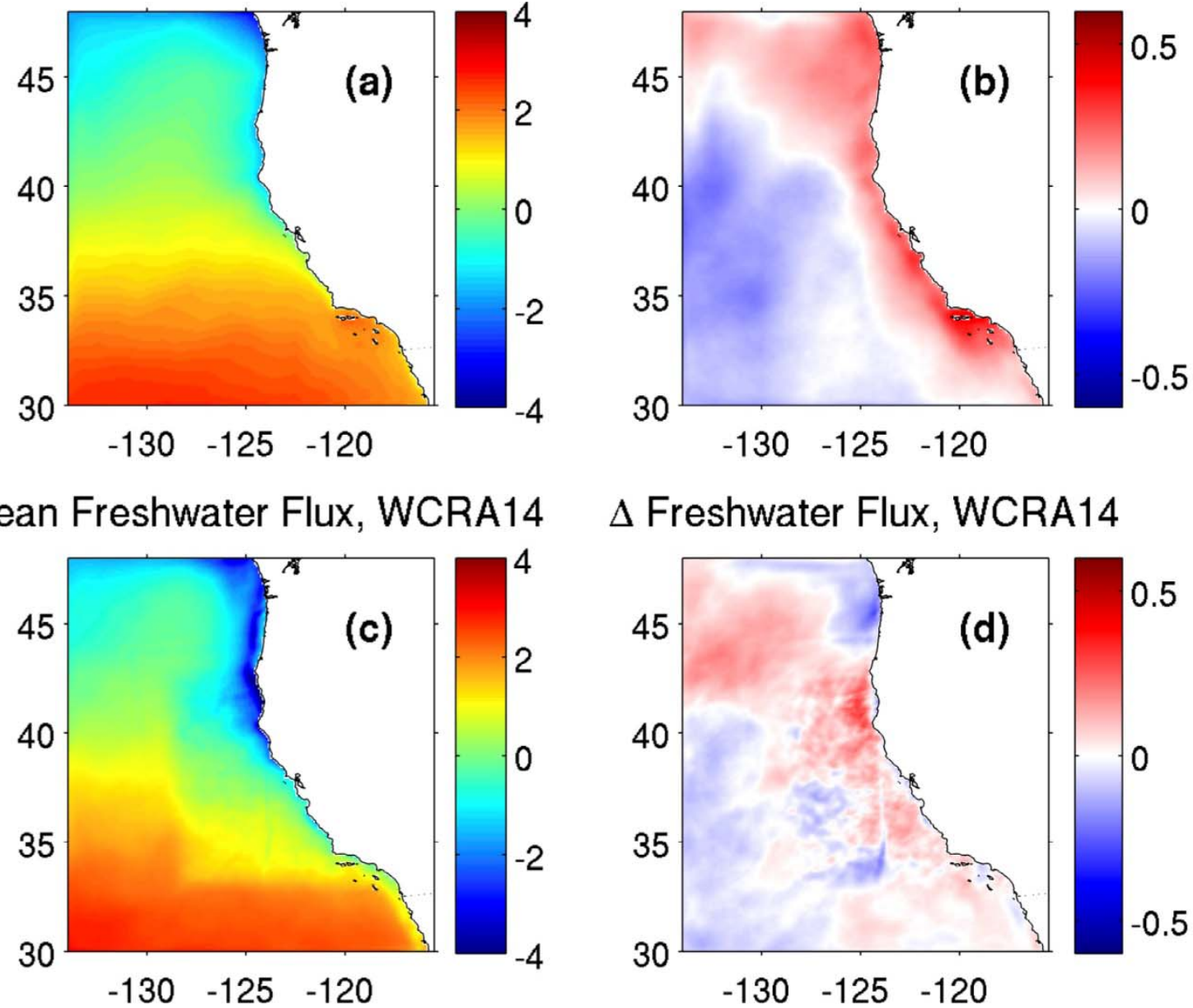

$\Delta$ Freshwater Flux, WCRA14

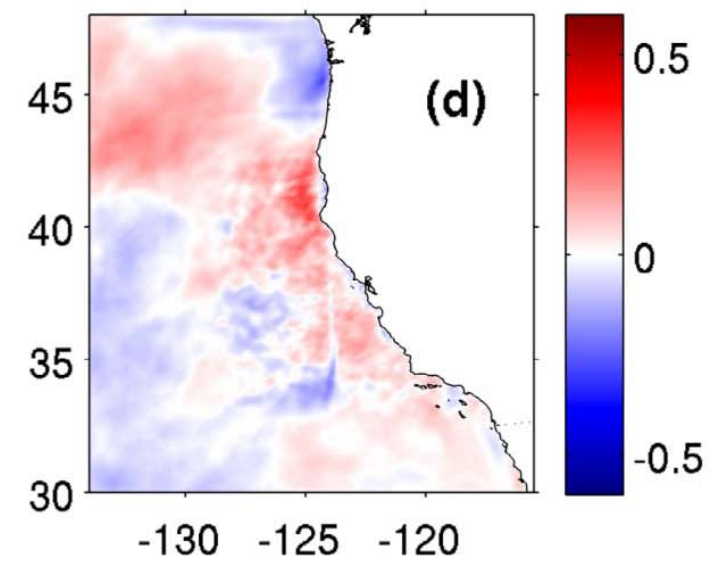

Figure 12: The mean posterior total surface freshwater flux $\left(\mathrm{mm} \mathrm{day}^{-1}\right)$ averaged over all assimilation cycles for (a) WCRA31, and (c) WCRA14. A positive flux is out of the ocean (i.e. excess evaporation over precipitation). Also shown are the differences between the posterior and prior surface freshwater flux for (cb WCRA31, and (d) WCRA14. 


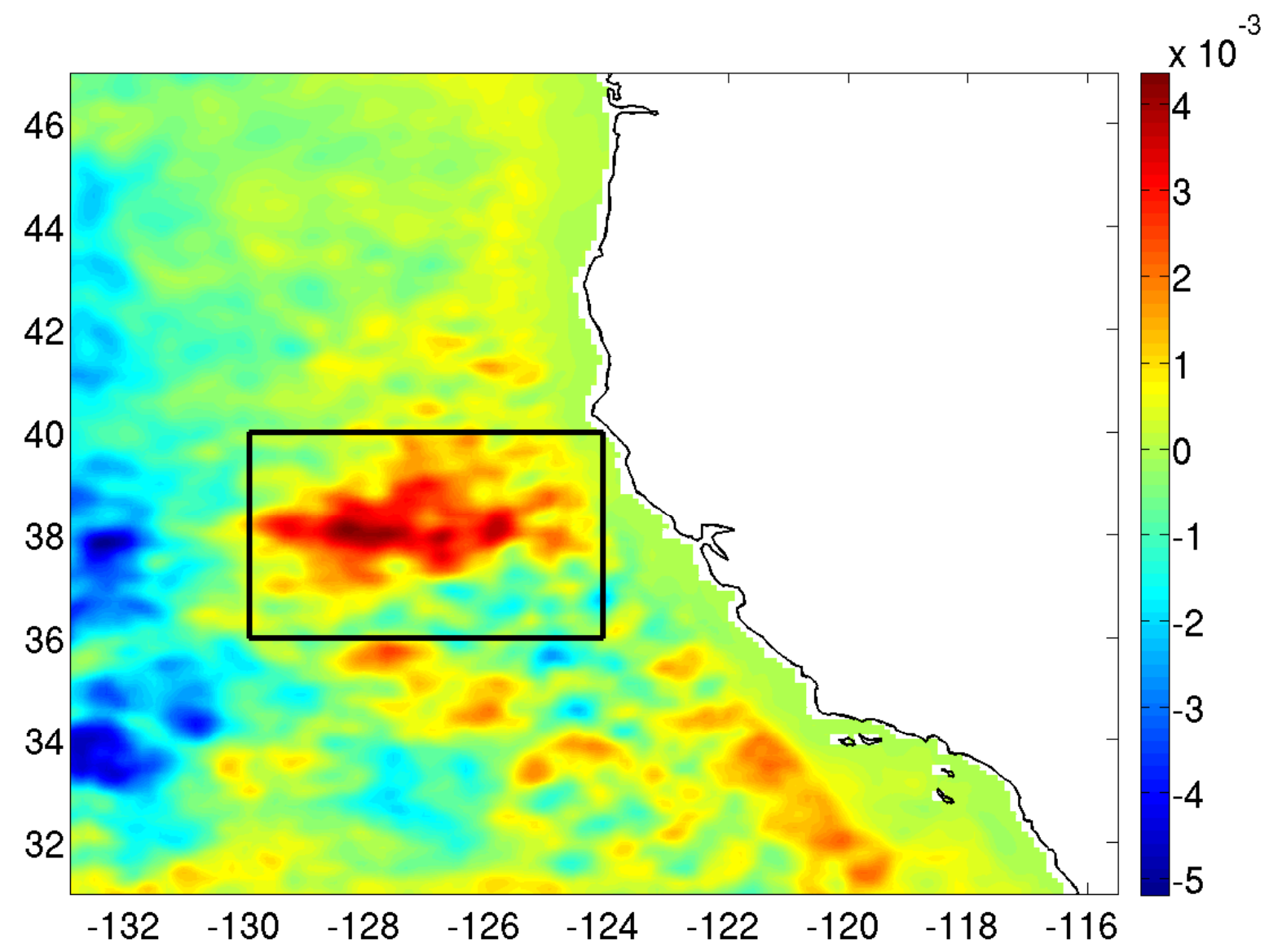

Figure 13: The time mean surface EKE difference between WCRA31 and the forward model run without data assimilation (TJoules). The region indicated by the black box is referred to in section 5.4. 

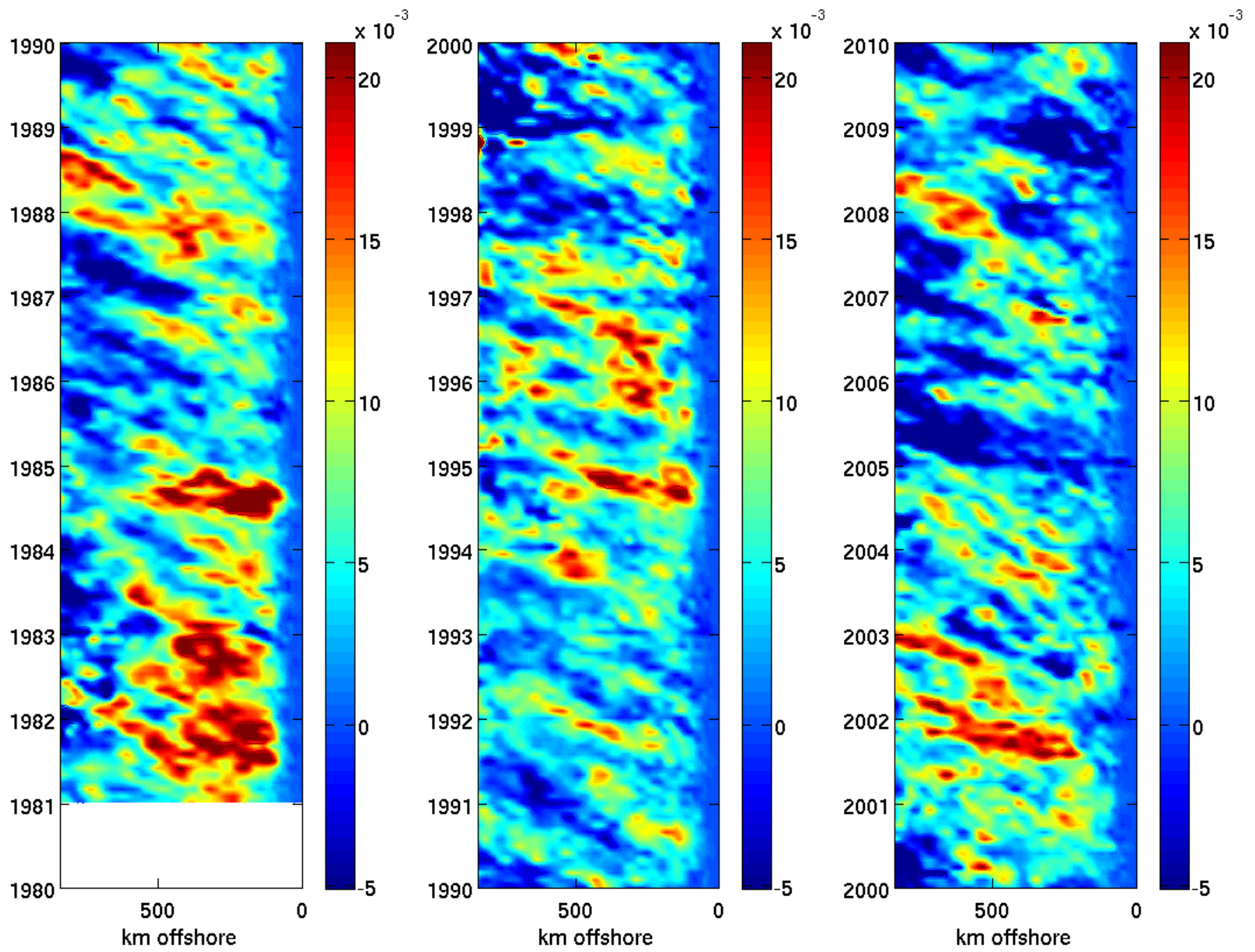

Figure 14: The difference in depth averaged EKE over the upper $500 \mathrm{~m}$ between WCRA31 and the forward model run without data assimilation and averaged between Point Conception $\left(34^{\circ} \mathrm{N}\right)$ and Cape Blanco $\left(43^{\circ} \mathrm{N}\right)$ as a function of offshore distance from the coast (TJoules). 

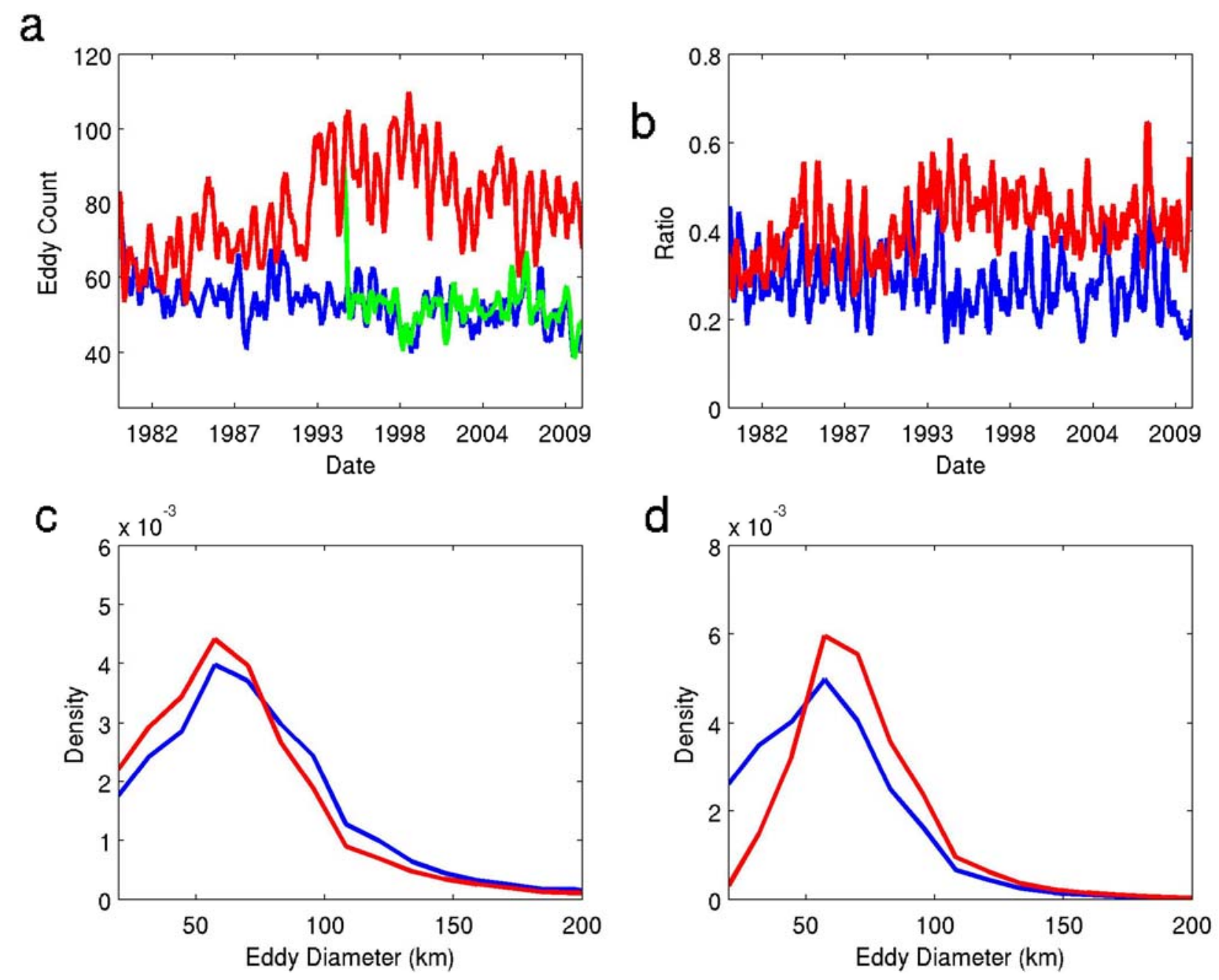

Figure 15: (a) Time series of the 3 month running mean of the total number of eddies in WCRA31 (red) and the forward model without data assimilation (blue). The number of eddies from a run of the model where data assimilation ceases on 17 Feb. 1995 is also shown (green).(b) Times series of the ratio of the 3 month running mean of the number of ageostrophic eddies to geostrophic eddies in WCRA31 (red) and the forward run (blue). (c) Probability density functions (PDFs) of eddy diameter in WCRA31 (red) and the forward model (blue). (d) The PDF for geostrophic eddies (red) and ageostrophic eddies (blue) in WCRA31. 

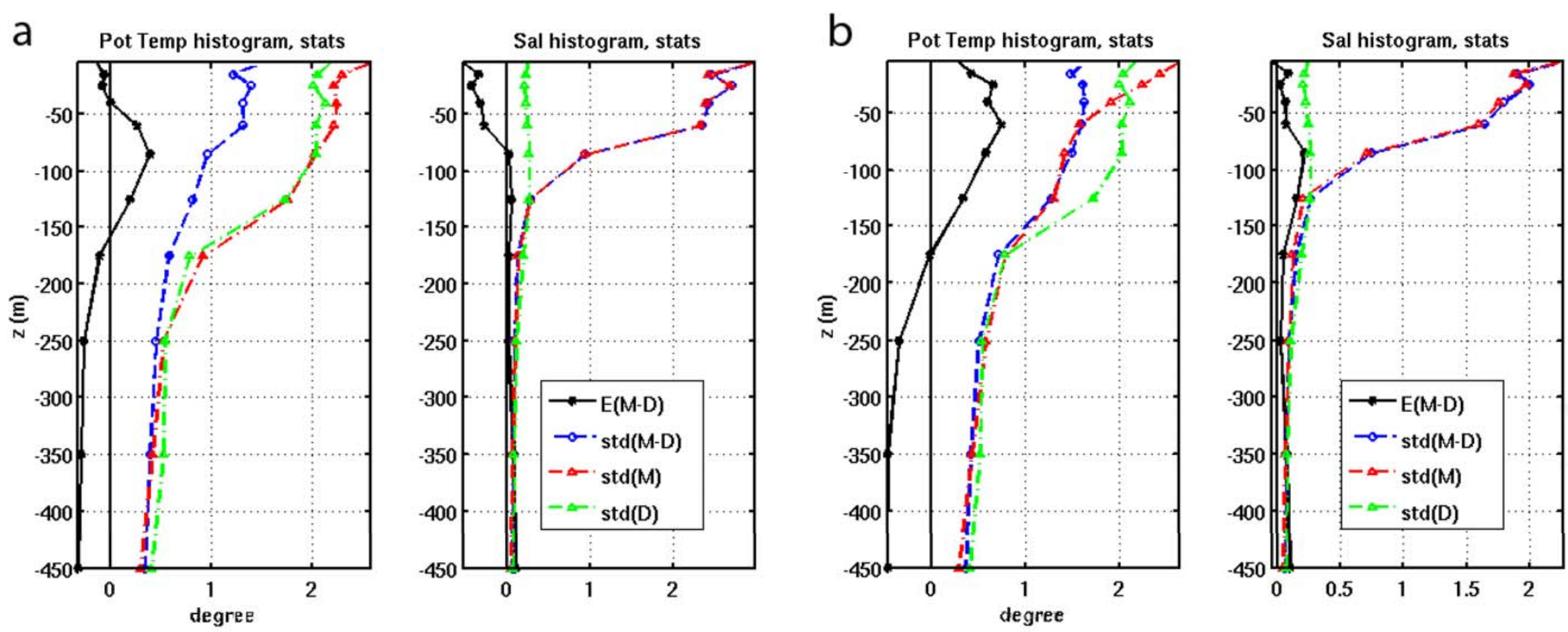

Figure 16: Vertical profiles of the comparison between the model and the CalCOFI observations for (a) WCRA31 and (b) the forward model run for the period Mar. 1990-Jul. 2007.

The statistics for temperature (salinity) are shown in the left (right) of each panel. The black line is the mean of the differences between the model (M) and the observational data (D). The standard deviation of the difference $M-D$ is shown in blue. The standard deviations of the model and the data are shown in red and green ,respectively. 